UCRL-ID-129902

\title{
Consequence Modeling for Nuclear Weapons Probabilistic Cost/Benefit Analyses of Safety Retrofits
}

\author{
Ted F. Harvey \\ Lin Peters \\ Franklin J.D. Serduke \\ Charles Hall \\ Douglas R. Stephens
}

January 1998

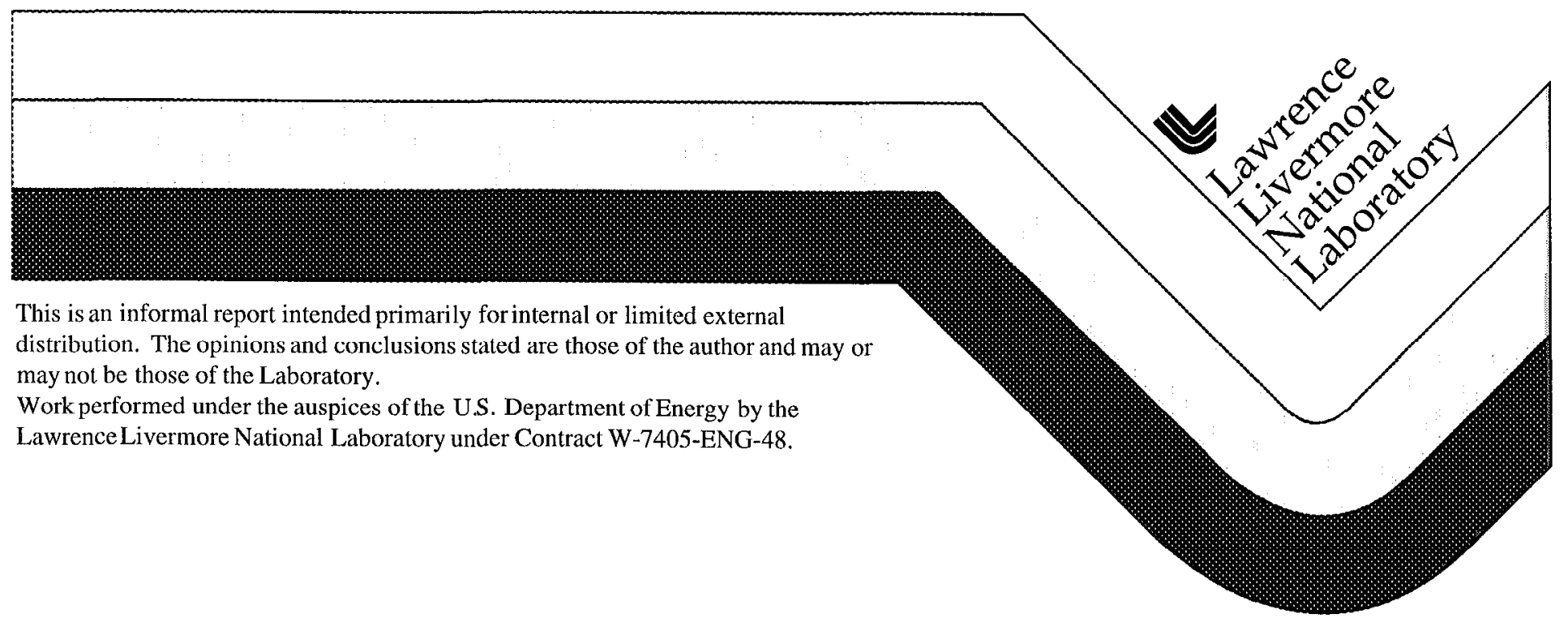




\section{DISCLAIMER}

This document was prepared as an account of work sponsored by an agency of the United States Government. Neither the United States Government nor the University of California nor any of their employees, makes any warranty, express or implied, or assumes any legal liability or responsibility for the accuracy, completeness, or usefulness of any information, apparatus, product, or process disclosed, or represents that its use would not infringe privately owned rights Reference herein to any specific commercial product, process, or service by trade name, trademark, manufacturer, or otherwise; does not necessarily constitute or imply its endorsement, recommendation, or favoring by the United States Government or the University of California The views and opinions of authors expressed herein do not necessarily state or reflect those of the United States Government or the University of California, and shall not be used for advertising or product endorsement purposes.

This report has been reproduced

directly from the best available copy.

Available to DOE and DOE contractors from the

Office of Scientific and Technical Information

P.O Box 62, Oak Ridge, TN 37831

Prices available from (423) 576-8401

Available to the public from the

National Technical Information Service

US Department of Commerce

5285 Port Royal Rd.,

Springfield, VA 22161 


\title{
Consequence Modeling for Nuclear Weapons Probabilistic Cost/Benefit Analyses of Safety Retrofits
}

\author{
Ted F. Harvey \\ Lin Peters \\ Franklin J. D. Serduke \\ Charles Hall \\ Douglas R. Stephens
}




\section{CONTENTS}

\section{Abstract}

Abbreviations

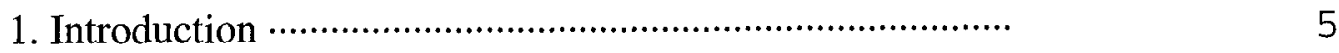

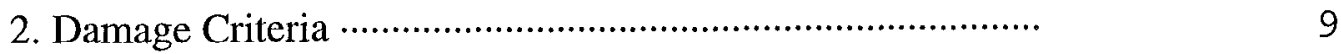

2.1 Pu Dispersal and Damages …...................................... 9

2.2 Nuclear Explosion Effects …..................................... 13

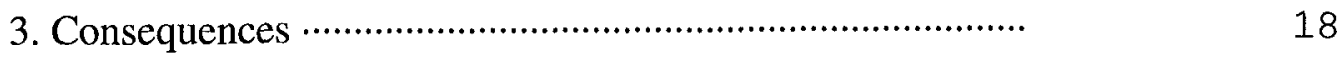

3.1 Pu and Fission-Product Dispersal ….............................. 18

3.1.1 Activity Lofting …......................................... 18

3.1.1.1 Fuel-Fire Lofting ...................................... 18

3.1.1.2 High-Explosive Detonation Lofting ….................. 20

3.1.1.3 Unintended Nuclear Detonation Lofting …................ 24

3.1.2 Activity-Size Distributions ….................................. 27

3.1.3 Cloud Dispersion Models ….................................. 29

3.2 Nuclear Prompt Effects …...................................... 31

3.3 Population Consequences Modeling ….............................. 33

3.4 Consequence Results …....................................... 36

4. Notes and References ….............................................. 40 


\begin{abstract}
The consequence models used in former studies of costs and benefits of enhanced safety retrofits are considered for (1) fuel fires; (2) non-nuclear detonations; and, (3) unintended nuclear detonations. Estimates of consequences were made using a representative accident location, i.e., an assumed mixed suburban-rural site. We have explicitly quantified landuse impacts and human-health effects (e.g., prompt fatalities, prompt injuries, latent cancer fatalities, low-levels of radiation exposure, and clean-up areas). Uncertainty in the wind direction is quantified and used in a Monte Carlo calculation to estimate a range of results for a fuel fire with uncertain respirable amounts of released $\mathrm{Pu}$. We define a nuclear source term and discuss damage levels of concern. Ranges of damages are estimated by quantifying health impacts and property damages. We discuss our dispersal and prompt effects models in some detail. The models used to loft the $\mathbf{P u}$ and fission products and their particle sizes are emphasized.
\end{abstract}




\section{Abbreviations}

ADPIC - Atmospheric Diffusion Particle-In-Cell

ADPIC_EL - Atmospheric Diffusion Particle-In-Cell with Explosion-Lofting

AF - Aerosolized Fraction

AFB - Air Force Base

AHD - Activity-Height Distribution

AIChE -American Institute of Chemical Engineers

AMAD - Activity Median Aerodynamic Diameter

ARAC - Atmospheric Release Advisory Capability

ASME - American Society of Mechanical Engineers

ASD - Activity-Size Distribution

AWRE - Atomic Weapon's Research Establishment

BEIR -

BOHS -

CEDE - Committed Effective Dose Equivalent

Clean Slate 1 - experiment

DCF - Dose Conversion Factor

DoD -Department of Defense

Double Tracks - experiment

EPA - Environmental Protection Agency

EPA-SL - Environmental Protection Agency's Screening Level, $0.2 \mu \mathrm{Ci} / \mathrm{m}^{2}$

ERAD -

ERDA - Energy Research Development Agency

FAFB - Flatland Air Force Base

FF - Fuel Fire

$\gamma$ - Gamma

HED -High Explosive Detonation

H-hour - time of nuclear detonation

ICRP - International Commission of Radiological Protection

KDFOC - K-Division Fallout Code

LCF - Latent Cancer Fatalities

Little Feller II - Nuclear test

LLNL - Lawrence Livermore National Laboratory

M/A - MATHEW/ADPIC

MATHEW - Mass-Adjusted Three-dimensional Wind Field

MP - Marker Particles

n - neutron

NTS - Nevada Test Site

P-95 - Population Circles

PCAS - Probabilistic Consequence Analyses

psi - pounds per square inch

rad - absorbed dose of $100 \mathrm{ergs} / \mathrm{gm}$

Redwing- Nuclear test

Small Boy - Nuclear test

UND - Unintended Nuclear Detonation

WGPu - Weapons-Grade Plutonium 


\section{Introduction}

This report is meant to help illuminate models we have used in previous reports. ${ }^{1}$ In those reports we have only considered high-technology plutonium ${ }^{2}$ weapons like those handled by the U.S. military. For normal operations these are designed to exacting safety standards, making them both safe to the public and military personnel. However, there are possibilities that a weapon could experience an extremely dangerous environment brought on by incredible accident or natural event. Under such conditions a weapon's safety features could fail and a nuclear disaster occur. This could happen at any stage in a weapon's life-cycle, including fabrication, storage, transportation, maintenance, deployment, retirement, or dismantlement. Brief descriptions of the accidents we have considered are given in Table 1.

Table 1 Brief descriptions of the three scenarios that we have considered in our probabilistic cost/benefit analyses.

\begin{tabular}{|c|c|}
\hline $\begin{array}{l}\text { Severe Fuel Fire } \\
\text { (FF) }\end{array}$ & $\begin{array}{l}\text { The weapon pit is breached after a long exposure to a hot fire, } \\
\text { followed by plutonium release to the fire, then combustion of the } \\
\text { plutonium. This would lead to entrainment of small plutonium oxide } \\
\text { particles into a rising fire plume. These would be transported to } \\
\text { significant distances. Depending on the fire dynamics, usually only a } \\
\text { small fraction, perhaps } 1-2 \% \text { of the oxidized plutonium would be } \\
\text { dispersed. Less than one percent of the plutonium would be } \\
\text { respirable (i.e., on particles with diameters less than three microns). }\end{array}$ \\
\hline $\begin{array}{l}\text { High-Explosive } \\
\text { Detonation (HED) }\end{array}$ & $\begin{array}{l}\text { Essentially all of the plutonium is aerosolized and lofted by the } \\
\text { explosion. High-order detonation is assumed, in which case all the Pu } \\
\text { turns into either liquid droplets or solid particles. These are entrained } \\
\text { into the rising hot debris cloud. Oxidation takes place as the cloud } \\
\text { rises. The largest particles detrain and settle to the surface around } \\
\text { ground-zero. Small respirable particles rise to the top of the stabilized } \\
\text { cloud where they diffuse downward, leading to highest respirable } \\
\text { doses somewhere downwind from ground-zero. Approximately } 20 \% \text { of } \\
\text { the plutonium is respirable. }\end{array}$ \\
\hline $\begin{array}{c}\text { Unintended Nuclear } \\
\text { Detonation (UND) }\end{array}$ & $\begin{array}{l}\text { There would probably be less than } 1 \mathrm{kt} \text { fission yield. Even so, there } \\
\text { would be incredible damages if the fission event were in a populated } \\
\text { area, occurring from "initial" and "delayed" nuclear phenomena. Initial } \\
\text { damages would be mainly caused by blast, fire, and prompt radiation. } \\
\text { In the first twenty-four hours, gamma-radiation from fallout of fission } \\
\text { products would be deadly. Fallout lethalities likely would be greater } \\
\text { than those from initial effects. During cloud passage, respirable Pu } \\
\text { near the ground would be of concern. Most Pu in the primary would } \\
\text { not have fissioned and about } 20 \% \text { would be respirable. It is most } \\
\text { likely that Pu from more than one nuclear weapon would be released; } \\
\text { we assume ten weapons. }\end{array}$ \\
\hline
\end{tabular}




\section{- Initial Mass Fractions}

Our source terms for dispersion codes consist of three submodels: (1) amount of material released to the atmosphere; (2) size-distribution of the material; and (3) heightdistribution of the material. We are mainly interested in source-term parameters affecting respirable-sized alpha emitters and fallout-sized gamma emitters. Study of these is best achieved by separating the radioactive aerosol into two size distributions: larger particles (fallout particles) with fall velocities greater than $1 \mathrm{~cm} / \mathrm{s}$; and smaller particles (respirable particles) with fall velocities less than $1 \mathrm{~cm} / \mathrm{s}$. Here we give "initial mass fractions", which are the overall normalization factors needed in dispersal models. "Aerosolized" fraction is defined here as the $\mathrm{Pu}$ mass fraction on particles having less than $500 \mu \mathrm{m}$ radius. For a fuel fire, all of the $\mathrm{Pu}$ can be oxidized and transformed to $\mathrm{PuO}_{2}$ aerosol particles with radii less than $500 \mu \mathrm{m}$, depending on fire parameters, e.g., temperature. ${ }^{3}$ However, fires usually do not produce sufficiently large updraft velocities to break the particles cohesive forces and loft all of the aerosols. For fires, we assume that only two percent is lofted and dispersed, with $0.05 \%$ being respirable. For an HED or UND, all $\mathrm{Pu}$ is assumed aerosolized, lofted, and dispersed, with $20 \%$ being respirable. (See Table 2).

For weapons using plutonium as fissile fuel, the $\mathrm{Pu}$ is found in the primary. Quantities of $\mathrm{Pu}$ vary from weapon to weapon, but might be as much as ten kilograms. We have assumed only one weapon is involved in the FF and HED scenarios. We assume a magazine of ten weapons explodes with HE detonations in the UND case, after one weapon undergoes a nuclear explosion. This results in the complete aerosolization and lofting of $100 \mathrm{~kg}$ of $\mathrm{Pu}$.

Table 2 Summary of initial mass fractions for our scenarios.

\begin{tabular}{|l|c|c|c|c|}
\hline & Pu Mass & Aerosolized & Lofted & Respirable \\
\hline FF & $10 \mathrm{~kg}$ & $20 \%$ & $2 \%$ & $0.05 \%$ \\
\hline HED & $10 \mathrm{~kg}$ & $100 \%$ & $100 \%$ & $20 \%$ \\
\hline UND & $100 \mathrm{~kg}$ & $100 \%$ & $100 \%$ & $20 \%$ \\
\hline
\end{tabular}

- Location

To estimate potential costs, an accident must be located relative to a population. There are locations where accidents are more likely to occur, for example, around an air force base. For our studies, we have chosen a representative location that we have named Flatland Air Force Base, Figure 1. Consequence-wise, this location falls between rural and urban cases. For a large metropolitan site, mitigation costs would be much larger; likewise, for a remote rural site, they would be much smaller. Agricultural land abuts the 
base on one side and surrounds "Flatland City", the adjacent urban area, so-named because there is very little topographical relief. Figure 1, shows computer generated overlays of population and geography. The total population is represented by "P-95 circles". Each has a latitude, longitude, population, and radius. The population density inside a circle is assumed uniform. Although all tallied people do not live inside the designated circles, the model was developed so that at least $95 \%$ of them do. The total numbers of people in the data base are included in the P-95 circles. For our study, the number of people at risk has been limited to those within $300 \mathrm{~km}$ of the accident site and totals about 900,000 people, including four thousand residents assumed living on the base.

The "accident site" is assumed to be near the northwest corner of the base, close to civilian housing located across the street. A worst case wind would blow roughly from the southeast. This would cause nuclear materials to be dispersed toward downtown "Flatland City" and, thus, would lead to the largest "population" dose (i.e., a dose integrated over time and summed over individuals). Also, people in nearby housing would receive lethal gamma-ray doses from fallout in the case of the unintended nuclear detonation.

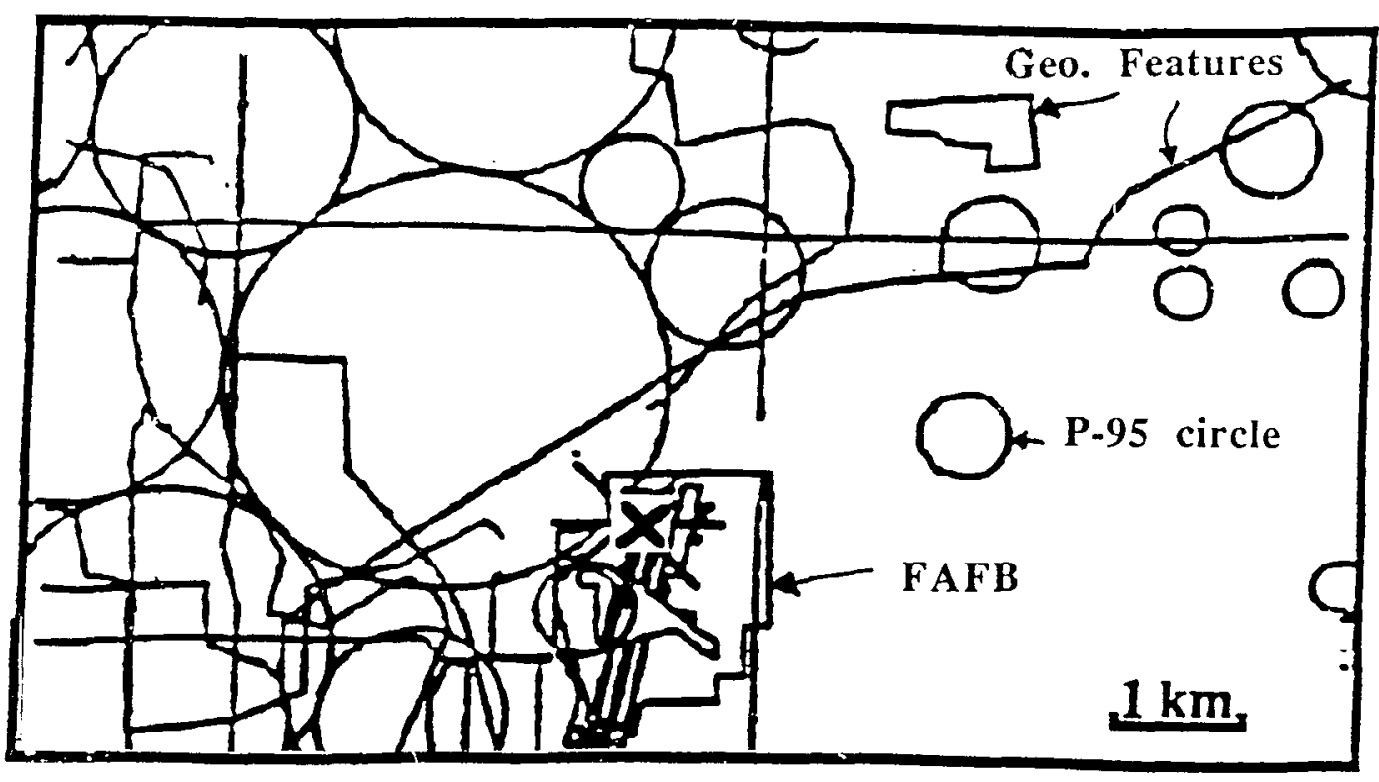

Figure 1 Flatland Air Force Base, geographical features and near-by population, A "Representative" Location. We assume four-thousand people reside on the base. Ten thousand people are on the base during normal working hours. $X$ shows the location of the hypothetical accident.

- Meteorology 
Radionuclide dispersal patterns will be heavily dependent upon meteorological conditions. Key atmospheric variables are surface and upper-air speeds and directions, atmospheric stability, and mixing layer depth. Values for the assessments were chosen to simulate conditions using a measured wind in the area of a military base. Anisotropy in the population distribution makes wind direction a most sensitive parameter. Directional probabilities are determined by seven years of hourly wind measurements ${ }^{4}$ taken over all stability classes and wind speeds at Flatland AFB. The windrose provides frequencies for each wind direction as shown in Fig. 2.

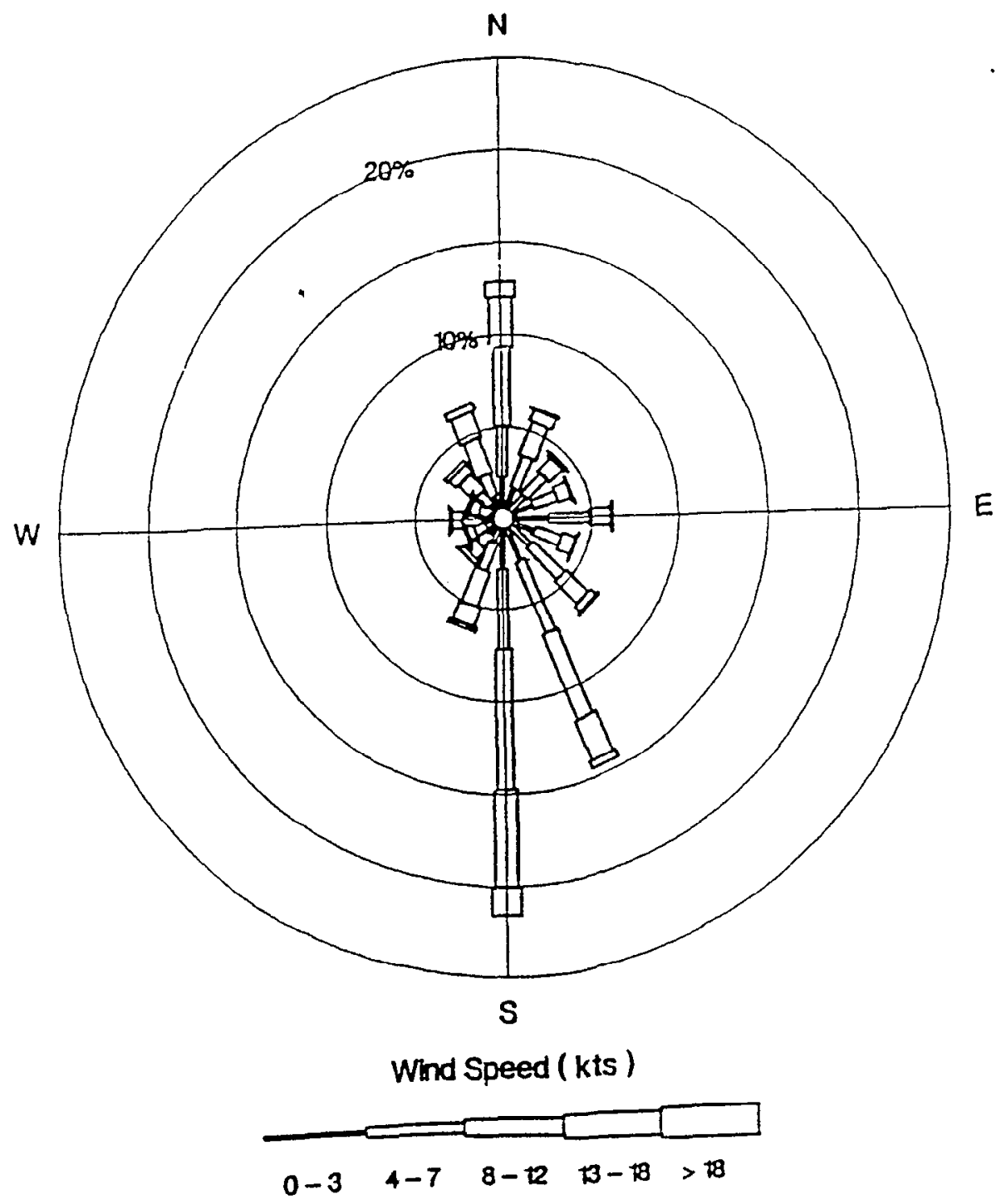

Figure 2 Ground-level wind direction and speed frequencies at FAFB. 
The atmosphere is assumed to be stable (Pasquill-Gifford type D) below a thermal inversion layer at $300 \mathrm{~m}$. This provides a relatively low ceiling, effectively putting a cap on how high the fission debris and $\mathrm{Pu}$ can diffuse for the FF and HED. The UND punches through and stabilizes with a cloud top at almost 4000 $\mathrm{m}$. The respirable $\mathrm{Pu}$ under our assumed "fumigation" conditions is trapped relatively close to ground. This causes higher ground-level doscs. We assume a low wind shear, which, for a given wind speed, leads to especially long dose patterns, putting a larger, more-distant population at risk. We assume no rain is falling, which for inhalation dose, is a conservative meteorological assumption. Wind speeds and directions versus altitude which were used are shown in Table 3.

Table 3 Wind vector versus altitude.

\begin{tabular}{|c|c|c|c|c|}
\hline Altitude (m) & 10. & 500. & 1000. & 5000. \\
\hline Speed (m/s) & 4. & 5. & 5. & 5. \\
\hline Direction (') & 20. & 40. & 40. & 40. \\
\hline
\end{tabular}

\section{Damage Criteria}

There are three primary hazards from a nuclear weapon dispersal accident: (1) plutonium dispersal. ${ }^{2}$ (2) fission radionuclides dispersal (initially hundreds of nuclides); and, (3) prompt effects (blast, neutron/gamma radiation, and thermal radiation). In this chapter, we first discuss long-lived impacts from alpha-emitting $\mathrm{Pu}$ isotopes and their daughters (\$2.1). In $\S 2.2$, we discuss damages unique to a nuclear explosion.

\subsection{Pu Dispersal and Damages}

During cloud passage, inhalation of respirable $\mathrm{Pu}$ is the main hazard for fuel fires and HE detonations. For a nuclear detonation, prompt effects and fallout are more damaging initially, fallout of unfissioned $\mathrm{Pu}$ (i.e., $~ 99 \%$ in our scenario) can lead to costly clean-up efforts over the long-term. Larger particles of $\mathrm{Pu}$ fall to the ground, starting near ground zero and extending for many kilometers downwind. Because of fear of resuspension of respirable particles, much of this fallout area would require cleanup or relocation. 


\section{- Source Term}

Our $\mathrm{Pu}$ source term is for weapons-grade plutonium (WGPu). By design, the WGPu reactor fuel undergoes less burn-up in the reactor and, thus, has less ${ }^{241} \mathrm{Pu}$ in its actinide mix than normal spent fuel. This leads to less gamma radiation from the resulting weapon, and, thus, less dose to those handling the weapon. Table 4 gives the main radionuclides in weapons-grade $\mathrm{Pu}$ just after reprocessing and when 15 years old. Alpha activity for 15 -year-old weapons-grade $\mathrm{Pu}$ is about $88 \mathrm{Ci} / \mathrm{kg}$. The beta activity is about 300 $\mathrm{Ci} / \mathrm{kg}$. Because biological effects of inhaled betas are substantially less than for alphas (See Table 4), we ignore beta effects. About two-thirds of the total inhalation hazard of $\mathrm{Pu}$ is from ${ }^{239} \mathrm{Pu}$.

Table 4 Weapons-Grade $\mathrm{Pu}$ for a 15-yr old weapon compared with its initial $\mathrm{Pu}$. The dose conversion factors (DCFs) are for inhaled Pu residing on particles that hydrodynamically behave like unit-density spheres with a diameter of $1.0 \mu \mathrm{m}$.

\begin{tabular}{|l|c|c|c|c|c|}
\hline & $\begin{array}{c}\text { Primary } \\
\text { Decay Mode }\end{array}$ & $\begin{array}{c}\text { Half-life } \\
\text { (years) }\end{array}$ & $\begin{array}{c}\text { Initial } \\
\text { Weight (\%) }\end{array}$ & $\begin{array}{c}\text { 15-yr } \\
\text { Weight (\%) }\end{array}$ & $\begin{array}{c}\text { DCF } \\
{[\text { rem/ } \mu \mathrm{Ci}]}\end{array}$ \\
\hline $238 \mathrm{Pu}$ & $\alpha$ & 87.7 & 0.040 & 0.036 & 288 \\
\hline $239 \mathrm{Pu}$ & $\alpha$ & 24100. & 93.3 & 93.3 & 308 \\
\hline $240 \mathrm{Pu}$ & $\alpha$ & 6540. & 6.00 & 5.99 & 308 \\
\hline $241 \mathrm{Pu}$ & $\beta, \gamma$ & 14.4 & 0.58 & 0.28 & 5 \\
\hline $241 \mathrm{Am}$ & $\alpha$ & 432. & 0.0 & 0.30 & 444 \\
\hline
\end{tabular}

\section{- Affected Person}

Once lodged in the lung, Pu remains in the body for many years. Thus, the dose is time-integrated, typically over a fifty-year period, giving a "committed" dose. Plutonium concentrations in air are converted to "rem" (radiation equivalent man) using the DCFs in Table 4. An organ-weighted dose conversion factor is used to calculate a 50-year CEDE (committed effective dose equivalent) of $3.2 \times 10^{8} \mathrm{rem} / \mathrm{Ci}$. A breathing rate of $3.3 \times 10^{-4}$ $\mathrm{m}^{3} / \mathrm{sec}$ is assumed. 5 Inhalation dose contours are based on Pu concentrations 1.5 meters above the surface. We also conservatively assume all respirable particles have a physical diameter of about $0.3 \mu \mathrm{m}$. To calculate the number of people that could expect reparation for being victimized, we require an "affected person" to receive at least 100-mrem CEDE. This is about one-third of annual background dose, and would cause no observable biological effects. 


\section{- Population Dose}

Population dose is the summed dose over individuals that have been exposed to low-level radioactivity. There would be no acute effects seen, but latent cancers would stochastically be expected in some individuals. This would lead to dire predictions of future cancer deaths and genetic mutations, leading to much concern. Thus, costly medical screening would probably be needed by many victims cxposed to low radiation levels.

In our model, population doses are estimated from a dose overlaid onto a population of P-95 circles. From these, we calculate expected latent cancer fatalities using recommendations in ICRP Publication $60^{6}$ and BEIR-V. 7 Two-thousand person-rem absorbed by a population has been equated to one latent cancer fatality. This is independent of the dose to individuals, i.e., it assumes a "no-threshold" dose, and uses the so-called "linear hypothesis," i.e., the damage, for example, caused by $10^{-3} \mathrm{rem}$ is equal to onethousandth that caused by one-rem.

\section{- Pu Clean-up}

After cloud-passage has occurred, there is a resuspension risk that could be more hazardous than that incurred during cloud-passage. Areal concentrations of $\mathrm{Pu}$ are calculated using all particle sizes. The majority of aerosolized mass forms on particles too big to be respirable. These large particles contribute mostly to fallout. Many detrain from the puff during cloud rise. Such particles, however, can be crushable and could transform into small enough particles to be respirable. ${ }^{8}$ The biggest particles formed are categorized as projectiles and produce a pattern of continuous ejecta around ground zero. These would be scattered in nearly a circular pattern, easily found and cleaned up. Particles larger than about $100 \mu \mathrm{m}$, if lofted, would fallout within about one kilometer.

Unlike undetcctable biological effects of breathing small amounts of $\mathrm{Pu}$ during cloud-passage, ground deposition will be easily observed. Cleanup issues will be unavoidable. Public outcries will occur over areas of the lowest levels of detectable $\mathrm{Pu}$. EPA draft regulations ${ }^{9}$ recommend a screening level (EPA SL) of $0.2 \mu \mathrm{Ci} / \mathrm{m}^{2}$. This is for samples collected at the surface to a depth of $1 \mathrm{~cm}$ and for particle sizes up to $2 \mathrm{~mm}$. This value is actually based on guidance of 1 millirad per year of alpha radiation to the pulmonary lung or 3 millirad per year to the bone. It is based on a resuspension model that is independent of $\mathrm{Pu}$ aerosol size. At $0.2 \mu \mathrm{Ci} / \mathrm{m}^{2}$ surface density, EPA, using a resuspension model, has calculated that there would be less than one-in-a-million chance of incurring a cancer death from living in the contaminated area. This value is not intended to be a hard and fast criterion for cleanup, i.e., soil at this level or higher would not necessarily need mitigation effort; rather, it is intended to provide a "conservalively based screening 
level," mainly for the purpose of eliminating lands below which further consideration is not necessary. Table 5 gives other levcls that might also affect clcanup costs.

Table 5 Various $\mathrm{Pu}$ levels of interest.

\begin{tabular}{|c|c|}
\hline $\begin{array}{c}\text { Level } \\
\left(\mathbf{n C i} / \mathbf{m}^{2}\right)\end{array}$ & Reason \\
\hline$<0.1$ & Detectable in laboratory \\
\hline $1-3$ & Background from testing \\
\hline$\sim 100$ & Field detection limit \\
\hline$<200$ & Rocky Flats land purchase \\
\hline 200 & EPA screening level \\
\hline 400 & Palomares: plowed soil \\
\hline 40,000 & Palomares: soil hauled away \\
\hline
\end{tabular}

Depth-integrating $\mathrm{Pu}$ from atmospheric testing gives about a hundred times less areal density than the draft EPA SL. Usually, this is almost all contained in the first ten centimeters of soil, where it is nearly uniformly distributed with depth. If one integrates the amount of $\mathrm{Pu}$ in the first centimeter (as this might be considered the only part important to resuspension), then background from atmospheric testing would be about three ordersof-magnitude less than the EPA SL. Pu from an accident would be detectable to levels lower than this, since actinide mixtures from atmospheric testing would be different. Cleanup to background plutonium contamination levels (about $0.1 \mathrm{nCi} / \mathrm{m}^{2}$ ) would be orders-of-magnitude more expensive than cleanup to the EPA SL. Also contamination levels are very sensitive to activity-size distribution, deposition velocity, and rainout. For example, choosing different parameters for the aerosol size distribution would substantially alter the deposition area covered at the EPA SL. Because the U.S. Government has not been able to provide a definitive cleanup standard and because dispersed $\mathrm{Pu}$ will be easily detectable at very low contamination levels, the cost of clean-up actions are highly uncertain. In this report we have used the EPA screening level to calculate clean-up areas. The summary of our Pu damage criteria is shown in Table 6.

Table 6 Summary of alpha-emitters damage criteria used in this study.

\begin{tabular}{|c|c|}
\hline Damage & Criterion \\
\hline Affected Person & $>100$ mrem inhaled \\
\hline
\end{tabular}




\begin{tabular}{|c|c|}
\hline Population Dose & $\begin{array}{c}2000 \text { person-rem inhaled }= \\
1 \text { Latent Cancer Fatality }\end{array}$ \\
\hline Cleanup Area & $\geq 0.2 \mu \mathrm{Ci} / \mathrm{m}^{2}$ \\
\hline
\end{tabular}

\subsection{Nuclear Explosion Effects}

A nuclear explosion in a populated area would be a catastrophe. ${ }^{10}$ Weapons are designed to be "one-point-safe" to accidental fission yield above four pounds of TNT. Thus, there is a much lower probability of releasing debris with a nuclear yield than releasing it by FF or HED. The adverse effects of an UND are strongly dependent on nuclear yield, prevailing meteorology, and how radiation effects the body at low dose rates. Nuclear yield depends on type of detonation, e.g., one-point to full-firing set. UND yields could range from tons to hundreds of kilotons. A high-yield UND in a populated area would be the worst nuclear accident that the world has ever known. Some scenarios are almost unthinkable; it could be much worse than Hiroshima, Nagasaki and Chernobyl combined. There could be tens of thousands of prompt deaths resulting from initial radiation, blast, heat, and possibly ensuing firestorm. Thousands of future civilian deaths could occur from radiation-induced cancers. Mutations could last for generations. Many military personnel would probably be killed. In the worst case, a whole city or base could be completely annihilated. Areas of urban, suburban, and agricultural land would be rendered unusable for long periods of time.

Initial radiation, thermal, and blast are effects essentially unique to a nuclear detonation. "Groundshine" occurs later due to delayed gamma radiation deposited on the ground as fallout. The main-time frame of concern for these effects is the first day, after which evacuation would probably mitigate further damages.

\section{- Prompt Effects}

Three prompt effects are blast, thermal radiation, and initial nuclear radiation. These effects occur within the first minute. A majority of structures will suffer some damage from overpressure, i.e., the pressure in excess of the normal atmospheric value. The distance to which this overpressure will extend depends on the yield or size of the explosion and the height of the burst. Prompt thermal radiation is defined as that emitted from the heated air of the fireball within the first minute. In a surface burst, $\sim 30 \%$ of the total energy yield is emitted from the fireball as thermal radiation. It contributes to overall damage by igniting combustible materials and causing skin burns and eye injuries to exposed individuals at distances where blast and initial nuclear radiations are insignificant. 
Initial nuclear radiations are highly-penetrating and harmful rays that accompany a nuclear explosion. These mainly consist of gamma photons and neutrons.

Figure 3 shows prompt-effects lethal areas for a surface-burst nuclear weapon as a function of yield. For low-yields, the lethal radius is dominated by prompt neutron/gamma radiation; for high-yields it is thermal radiation (light and heat). Because of induced firestorms, high-yield lethalities could extend out to roughly ten kilometers. The fallout area is also shown. Because it is wind-driven and roughly cigar-shaped, for high yields people could be at lethal risk to hundreds of kilometers. It is possible that emergency response could help mitigate fallout, but it would have to be extremely well planned. Much of the dose would be incurred soon after fallout starts. Without decent training, rescuers could receive lethal dnces much like those to firefighters at Chernobyl, for example.

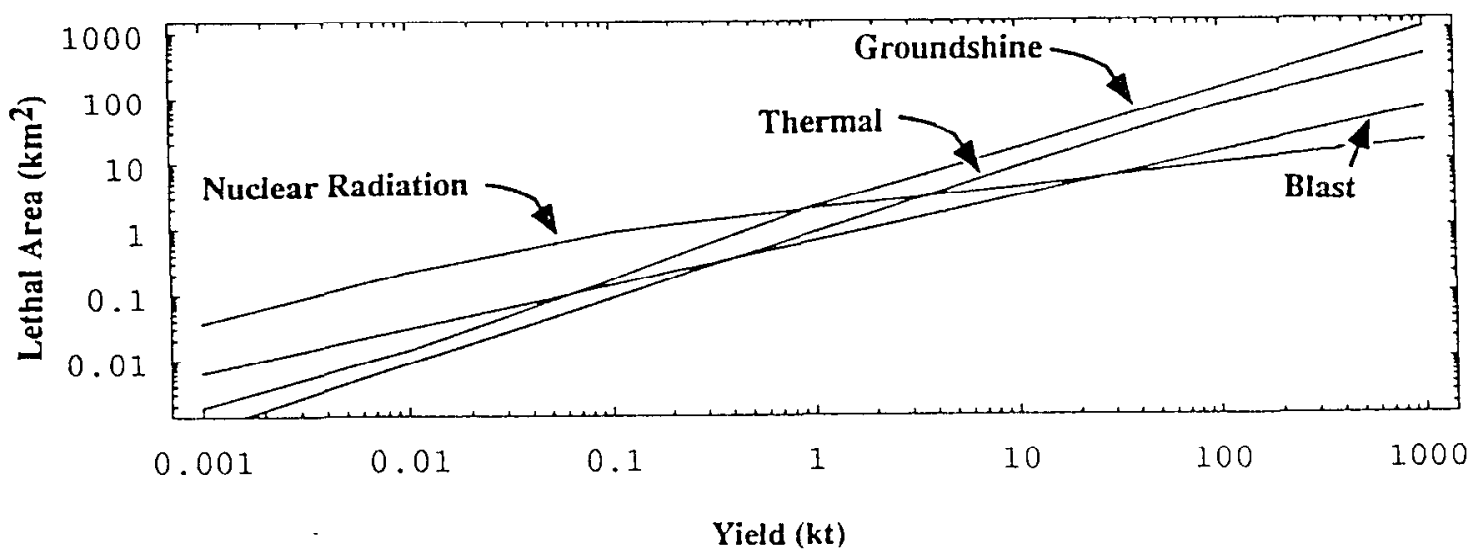

Figure 3 Lethal areas covered by free-field prompt effects and 24-hrs of unsheltered gamma radiation from a fission event.

\section{- Delayed Gamma Activity}

For a $1 \mathrm{kt}$ explosion there are $1.45 \times 10^{23}$ fissions. The two fission fragments carry away most of the energy as coulomb repulsion energy. This produces a population of radioactive fission products that is double-peaked in mass as shown in Figure 4. These products are "neutron-rich", and begin to beta decay immediately, producing daughters usually in excited nuclear states decaying to ground states by emitting gamma rays. Each of the atomic-weight chains (for masses from $82-155 \mathrm{for} \mathrm{Pu}$ ) is made up of a set of isobars (having the same number of nucleons) like the 133-nucleon case shown in Fig. 5. Beta decays are caused by neutrons emitting electrons of various energies with coincident neutrinos, as the parent nuclides approach a nucleus with stable numbers of neutrons and protons.

Gamma radiation from the fission debris at one hour after detonation is about 430 MCi. ${ }^{11}$ At this time the gammas average about $0.7 \mathrm{MeV}$ per photon, and decay following 
a $t^{-1.2}$ decay law. 12 For every factor-of-seven in time, the radiation field falls off by a factor of ten. Taking into account ground roughness, and spreading fission debris uniformly over one square-mile at one hour after the explosion, the DCF for fission debris gammas at one meter above a grassy plane is $\sim 2000 \mathrm{rem} / \mathrm{hr} / \mathrm{kt}$.

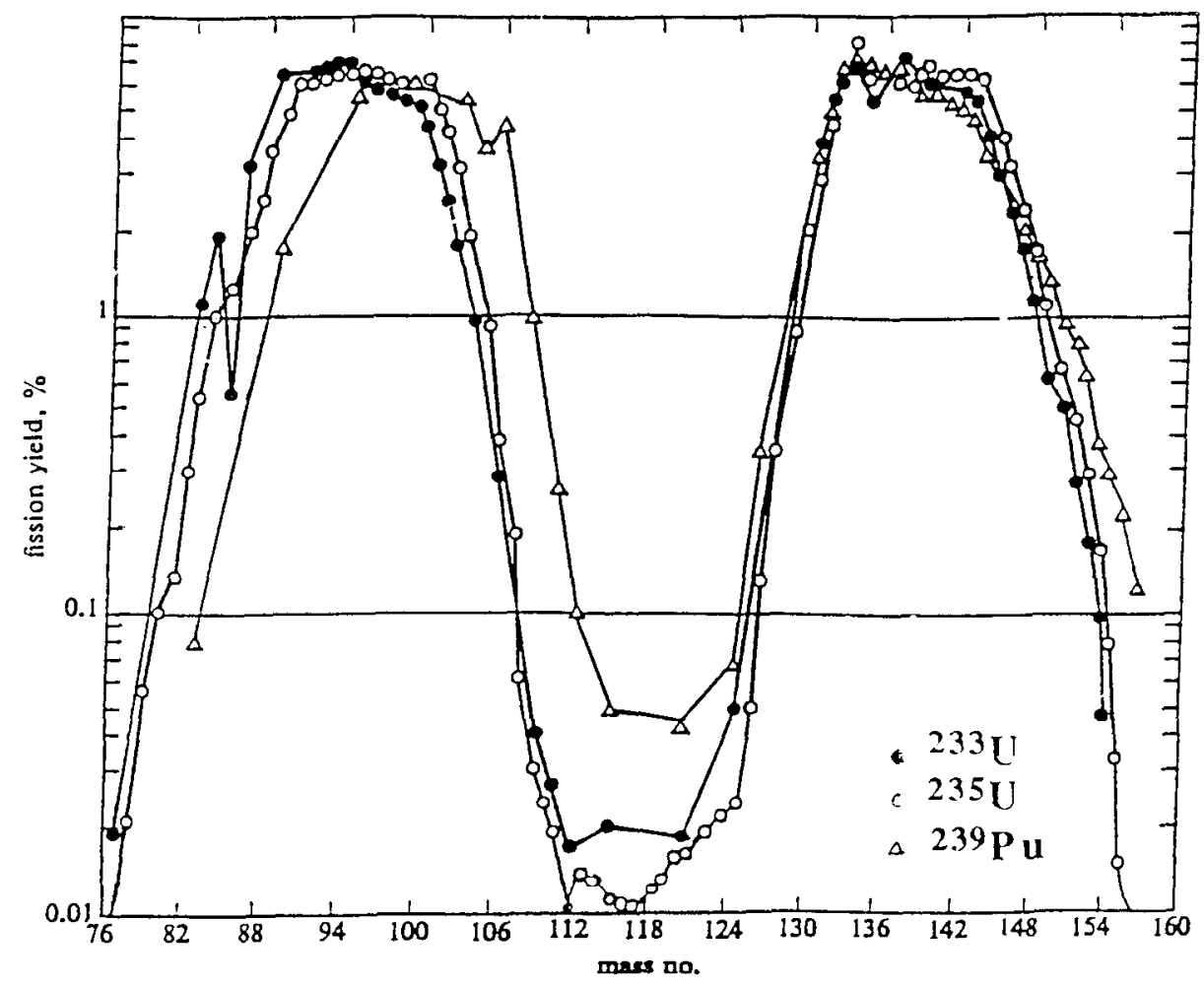

Figure 4 Double-humped fission-yield curve versus atomic weight for ${ }^{233} \mathrm{U},{ }^{235} \mathrm{U}$, and ${ }^{239} \mathrm{Pu} .13$

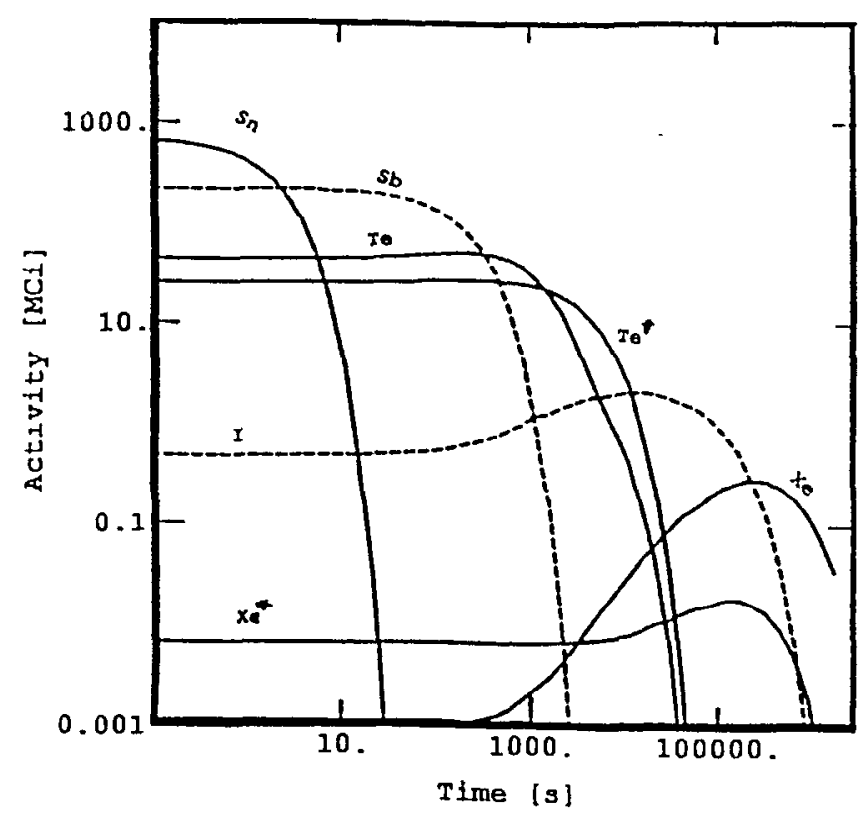


Figure 5 Activity versus time for ${ }^{239} \mathrm{Pu}$ 133-nucleon decay chain, for fission spectrum neutrons. The chain decay proceeds from element to element as $\mathrm{Sn} \rightarrow \mathrm{Sb} \rightarrow$ $\mathrm{Te} \rightarrow \mathrm{I} \rightarrow \mathrm{Xe}$, gaining a proton and losing a neutron in each decay. "** indicates an excited state that usually decays by emitting a gamma photon.

\section{- Damages from 1-kt Nuclear Explosion}

Cloud-passage immersion and inhalation doses would be an important effect for low-yield UNDs, causing projected latent cancer deaths and mutations. For higher yields, radiation doses would be dominated by fallout. At low and intermediate yields rainout would also be an important effect. Global fallout from higher yields would occur over months and years. Rainout would lead to Pu hotspots, substantially above background in many places in the Northern Hemisphere. Some of these hotspots would probably be within major cities. Patterns would be similar to those produced by Chernobyl.

Besides lethal levels of gamma radiation from fission products, civilian authorities would be concerned with low levels of beta and alpha radiation, ${ }^{14}$ which could be measured to extremely low levels for specimens of top soil analyzed in the laboratory. ${ }^{90} \mathrm{Sr}$ and ${ }^{137} \mathrm{Cs}$ would he major problems to the food supply for tens of years. In the first few weeks ${ }^{131}$ I would be a concern. Prophylactic iodine would probably be administered to children, just as was done in Poland as the Chernobyl reactor burned. Like the aftermath of Chernobyl, farmers would again need to destroy contaminated crops and herds. Food pathways would need to be closely monitored. Resuspension of Pu would be a major problem. Civilian health authorities would likely take the prudent approach (which is also the standard one used by the Health Physics community); that is, they would use the "no threshold, linear hypothesis" to predict the number of people that would die of latent cancers. Estimates of many thousands of latent cancer fatalities would occur, depending on the yield and local population. In the aftermath of an UND, basing U.S. nuclear weapons near civilian populations would be strongly questioned. Such an accident could put the current U.S. nuclear weapons postures under major duress.

Figure 6 shows the whole-body gamma-radiation fallout contours ${ }^{15}$ for dose received in the first day after a 1-kt detonation. Because of the rapid decrease in dose rate, most of the dose would be received in the first few hours. The prompt lethal radius is 0.9 $\mathrm{km}$. It is shown as a dashed circle. Contours of $\mathrm{Pu}$ deposition and inhalation dose are 
similar for fires and $\mathrm{HE}$ detonations and are approximately scalable by the amount of $\mathrm{Pu}$ released (See Fig 13).

Fallout effects to a population are strongly dependent on the wind direction. Longterm effects of a UND are caused by area contamination of long-lived radionuclides, mainly caused by fallout. The major long-term nuclides are ${ }^{137} \mathrm{Cs},{ }^{90} \mathrm{Sr}$ and ${ }^{239} \mathrm{Pu}$. For low yields, the dominant problem is ${ }^{239} \mathrm{Pu}$. As the yields get higher, the dominant agricultural problem is ${ }^{90} \mathrm{Sr} .{ }^{16}$ For our scenarios, $\mathrm{Pu}$ dominates the long-term clean-up problem. In Table 7 we summarize our effects criteria for a fission explosion.

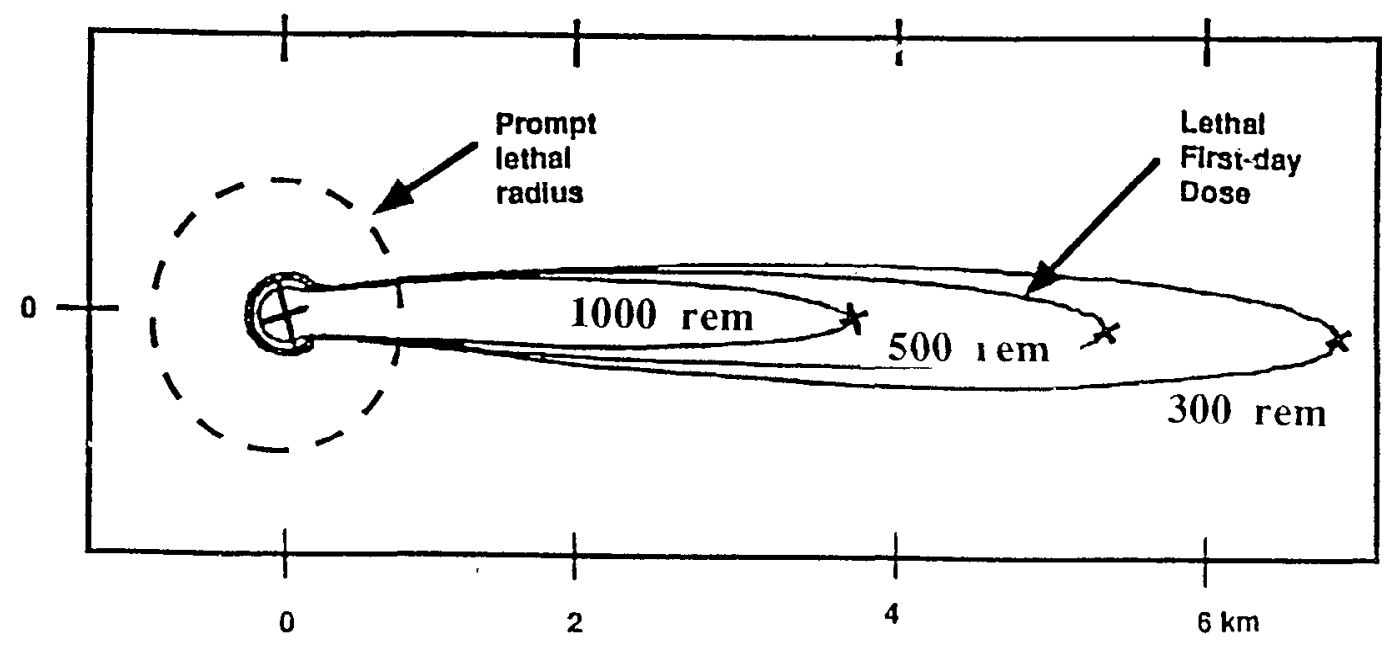

Figure 6 This figure shows gamma radiation fallout contours and lethal prompt effects radius for 1-kt UND integrated for $24 \mathrm{hr}$.

Table 7 First-day and long-term nuclear fission effects criteria.

\begin{tabular}{|l|c|c|}
\hline Damage & Lethal & Injury \\
\hline First-day & $>5 \mathrm{psi}$ & $>2 \mathrm{psi}$ \\
\hline Blast & $>500 \mathrm{rems}$ & $>100 \mathrm{rems}$ \\
\hline $\mathrm{n} \& \gamma$ Radiation & $>10 \mathrm{cals} / \mathrm{cm}^{2}$ & $>2 \mathrm{cal} / \mathrm{cm}^{2}$ \\
\hline Thermal Radiation & $>500 \mathrm{rems}$ & $>100 \mathrm{rems}$ \\
\hline 24-hr Fallout $\gamma$ Radiation & & $>100 \mathrm{mrem}$ \\
\hline Long-term &
\end{tabular}




\begin{tabular}{|l|l|l|}
\hline Latent Cancer Fatality & 2000 person-rem & \\
\hline Cleanup Area: ${ }^{137} \mathrm{Cs}$ & & $3.0 \mu \mathrm{Ci} / \mathrm{m}^{2}$ \\
\hline Cleanup Area: ${ }^{90} \mathrm{Sr}$ & & $0.2 \mu \mathrm{Ci} / \mathrm{m}^{2}$ \\
\hline
\end{tabular}

The first three criteria in Table 7 occur in the first minute. The fallout groundshine is integrated for 24 hours. All effects are calculated for unsheltered individuals. Effects at these levels would be immediately noticed. The long-term effects would lead to long-term costs, either in chronic health effects, potential litigation, or clean-up costs. ${ }^{17}$

\section{Consequences}

A nuclear weapon accident occurring in a populated area would result in a set of consequences felt for decades. Such consequences have large prediction uncertainties depending on: type of accident; number of weapons involved; severity of the accident; local population size; weather; and, the warning and sheltering of nearby people. We limit our discussion to major health effects and property damages from plutonium dispersal, as well as effects from nuclear yields. We assume a weapon is $15 \mathrm{yrs}$ old at accident time (See $\$ 2.1$ for source terms).

In this chapter, we first discuss models and assumptions used for dispersal calculations (both Pu and gamma groundshine). Then, we discuss prompt effects for a fission explosion. Our overall results are presented in tabulated form in $\$ 3.4$ as health effects to people and property damages. A Monte-Carlo calculation for a fuel fire shows how physical uncertainties propagate to produce a large range of possible results. Such ranges are used to help estimate probabilistic benefits in our cost/benefit studies. ${ }^{1}$

\subsection{Pu and Fission-Product Dispersal}

In this section, we discuss modcls that loft Pu and fission products, the sizes of the aerosol lofted, and the transport of the nuclides through the atmosphere. The amount of source term is given in Table 2 .

\subsubsection{Activity Lofting}


Our lofting models are dynamic for the fuel fire and HE detonation. Initial conditions for the FF and HED are at $t=0$. The particles are followed throughout the cloudrise period. They rise and disperse with the hot cloud. Large particles fall out while the cloud rises. For the nuclear detonation we use an empirical model of fallout that starts with an "effective" cloud at stabilization at roughly five minutes.

\subsubsection{Fuel-Fire Lofting}

$\mathrm{Pu}$ lofting depends on the activity-size distribution (ASD), energy release, and meteorological conditions. Our distribution of activity versus time with respect to altitude, the activity-height distribution (AHD), is given by the Briggs' model and a particle coupling model. ${ }^{18-20}$ The Briggs' model is a highly regarded model introduced in 1965 that has been validated against many observations spanning a large range of measurements and energies. It has been revised and improved several times. Of those engaged in modeling emissions from stacks, an informal survey indicated as high as $75 \%$ might be using Briggs' model, including EPA. ${ }^{21}$ Basic phenomena modeled are kinetic energy of mass flux, sensible heat, and atmospheric stability as determined empirically by temperature lapse rate. Briggs' modcl was originally devcloped using techniques of dimensional analysis. Proportionality constants in the model were determined by comparing model results to observations.

The plume buoyancy is determined by the power of the fire. We need the energy release versus time to establish this. We assume a fuel leak rate of $150 \mathrm{gal} / \mathrm{min}$, resulting in a pool fire that equilibrates at about $14 \mathrm{~m}$ diameter, which releases buoyant heat at a rate of $110 \mathrm{MW}$. The pit is assumed to see a fire temperature above $1000^{\circ} \mathrm{C}$. After approximately one hour, the material surrounding the pit burns through and solid or molten $\mathrm{Pu}$ is burnt, releasing $\mathrm{PuO}_{2}$ aerosol for 30 minutes. The key source-term and lofting model parameters are summarized in Table 8 . Figure 7 shows the activity-height distributions of particles at eight minutes after initial release viewed from the side and above.

\section{Table 8 Key parameters for the fuel fire case.}

Pu in fire $(10 \mathrm{~kg})$

Aerosolized Fraction (AF) $=0.5$

Pu Alpha Specific Activity $(0.088 \mathrm{Ci} / \mathrm{g})$

Lofting Model

Lofted Fraction (0.04 AF)

Fuel Burning (150 gal $/ \mathrm{min})$
Fallout Model

Activity Size Distribution

Truncated Lognormal
Respirable Model

Respirable Fraction (0.001 AF)

Particle Aerodynamic Diameter $(1 \mu \mathrm{m})$ 
Burning Pool Diameter (14 m)

Heat Emission Rate (110 MW)

Atmospheric Stability (neutral)

Height to Inversion $(300 \mathrm{~m})$

Pu Release Rate $(5.6 \mathrm{~g} / \mathrm{s})$

Pu Release Duration (30 min)

Atmospheric Lapse Rate $\left(0.006^{\circ} \mathrm{C} / \mathrm{m}\right)$
Min Radius $(10 \mu \mathrm{m})$

Max Radius $(500 \mu \mathrm{m})$

Median Radius $(160 \mu \mathrm{m})$

Geo. Std. Dev. (4.0)

Particle Density $\left(1 \mathrm{~g} / \mathrm{cm}^{3}\right)$

One of our meteorological conditions is a conservatively chosen thermal inversion at $300 \mathrm{~m}$. This provides a cap to vertical diffusion and keeps the $\mathrm{PuO}_{2}$ closer to the ground, causing more dose to the local population than plumes lofted to higher elevations. Below the inversion layer a neutral buoyancy is assumed. An important meteorological parameter for plume rise is the lapse rate (decrease in temperature with altitude). We have chosen $0.006^{\circ} \mathrm{C} / \mathrm{m}$.
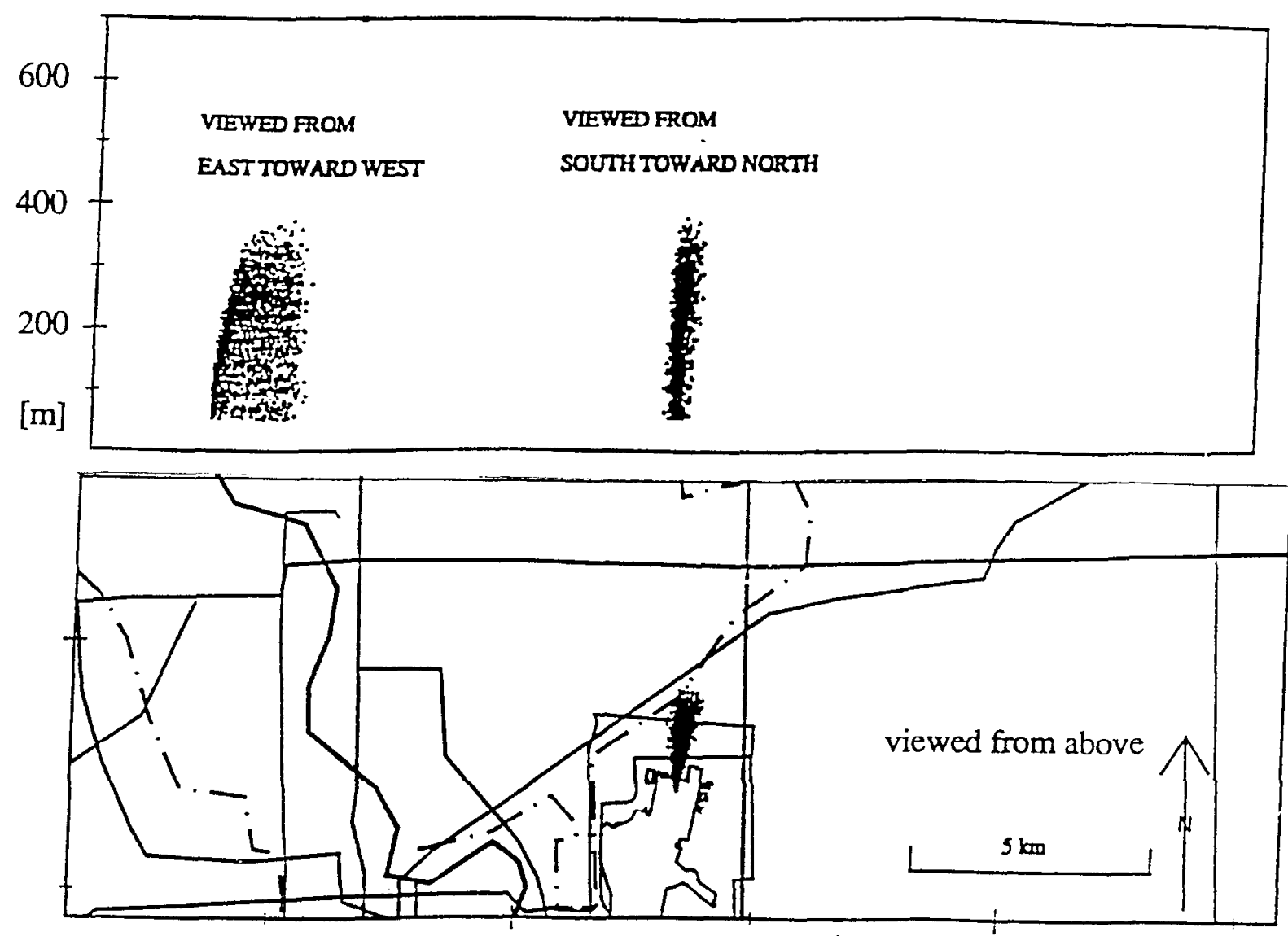
Figure 7 Activity-height distributions of particles for fuel fire at eight minutes after initial release. The aspect ratio in the top figure is 10:1.

\subsubsection{High-Explosive Detonation Lofting}

The phenomenology of an HED rising fireball starts with its explosive energy. This creates a hot buoyant air mass and a pulverized $\mathrm{Pu}$ aerosol. Most $\mathrm{Pu}$ is initially suspended inside the air mass. Surrounding ambient materials are entrained as the hot gas rises toward "stabilization". The hot air formed just after detonation is initially very buoyant, having an initial density about $80 \%$ of the surrounding air. In general, a 3-D hydrodynamic, thermodynamic, and aerosol physics model should be employed to attempt to fully capture the physical complexity of this problem. However, in our work for practical considerations many simplifying assumptions have been necessary.

\section{- Explosion-Lofting Model}

Initial conditions of the plume can be dry or contain substantial amounts of water vapor, which can condense during cloud-rise, adding latent heat and increasing stabilization altitude. In stable atmospheres, the cloud will stabilize in the lower troposphere (usually below $1 \mathrm{~km}$ ). Empirical models of stabilized clouds are often used to initialize dispersion models. In most cases, such models have not predicted "in-close" deposition patterns or inhalation doses. Since they conserve Pu, they do not accurately predict far-range effects everywhere either. A cloud-rise model called ERAD that takes some ambient air conditions into account and, thus, better predicts in-close consequences has been developed by Boughton and Delaurentis. ${ }^{22}$ Following Boughton, a similar model has been blended into the front-end of LLNL's ADPIC code. This model is termed ADPIC_EL (ExplosionLofting) in this report. It has been used to make our predictions. Briefly, the code predicts a time evolution of the physical and thermodynamic properties of a buoyant cloud formed after an HE explosion. The model is based on integrating three-dimensional equations conserving mass, momentum, and energy. The cloud is assumed to be spherical and in a well-mixed state shortly after detonation. It is composed of an equilibrium mixture of dry air and water. The ambient atmosphere is assumed to be horizontally homogeneous and constant with time. The diameter of the cloud is assumed small compared to significant changes in the atmosphere. These assumptions reduce the integral equations defining the cloud to a set of ordinary differential equations, which can be solved for (1) cloud radius, (2) cloud top, and (3) temperature. The solutions are sensitive to input parameters 
describing ambient air conditions, especially temperature change with altitude. The effects of buoyancy, entrainment, and drag forces are included. The initial size and conditions of the cloud are determined using atmospheric conditions and $\mathrm{HE}$ explosive yield.

\section{- ADPIC_EL Validation}

The accuracy of the cloud-top calculation by ERAD has previously been validated using the Double Tracks and Clean Slate 1 shots, along with other HE data sets. 22 Calculated cloud-top heights were well within a factor of two (usually within $25 \%$ ) of the observed values for a range of explosive amounts. Previous validation studies comparing ADPIC model results to tracer data have been made in both simple and complex terrain. ${ }^{23}$

To test the ADPIC_EL implementation of Boughton's prescription, the predicted cloud top was compared to observed cloud heights from Double Tracks and Clean Slate 1 (See Fig 8 for CS1 results). ${ }^{24}$

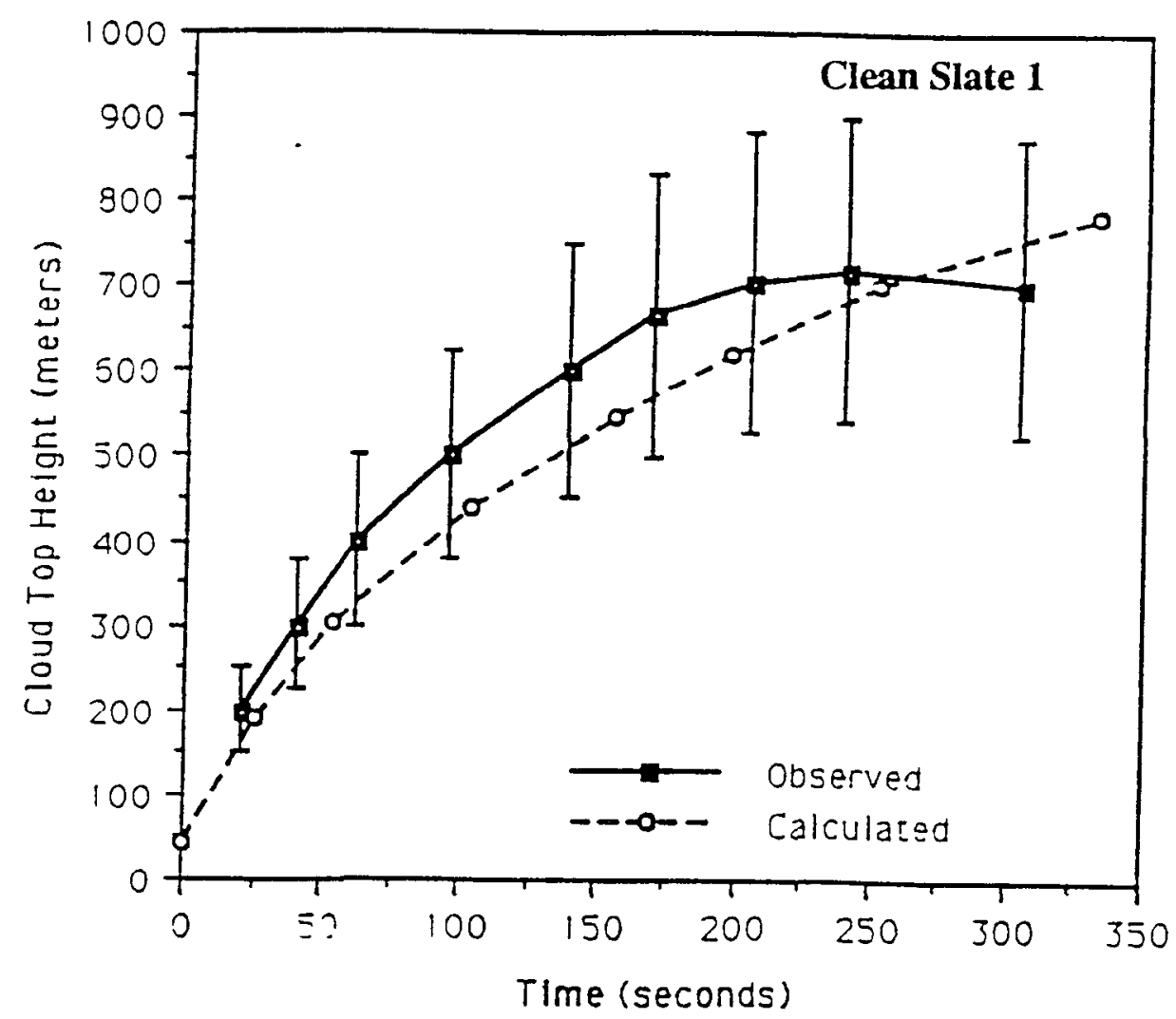

Figure 8 ADPIC_EL predictions compared with observed top of visible cloud. 


\section{- Aerosol-to-Cloud Coupling}

Once the cloud's time-dependence has been determined, coupling the buoyant bubble to the aerosol is required.20 This coupling is significantly different in ADPIC_EL than in ERAD. There are two considerations in coupling ADPIC marker particles (MPs) to the rising cloud. These are: (1) initial configuration of the MPs in the cloud; and, (2) their subsequent motion as affected by the buoyant sphere, its advection, particle diffusion, and particle settling. Figure 9 depicts the ADPIC_EL implementation of this coupling. All of the MPs are initially loaded into the spherical cloud at $t=0$. They start with a spatial 3-D truncated Gaussian distribution. The radial MP cutoff values equal the initial spherical bubble radius. The standard deviations of the MP cloud are scaled to the bubble radius and adjust the "flatness" of the truncated distribution. For surface explosions, we assume the edge of the sphere starts tangent to the ground.

As the bubble rises, it is composed of an environment of enhanced turbulence, with entrainment of ambient air occurring at its surface. Particles remaining inside the bubble are treated differently than those moving outside it. One difference is ambient diffusion is neglected. In addition, a fraction of the bubble's vertical velocity is applied to each MP. This MP vertical velocity is calculated as a function of its distance from the bubble center :

$$
\mathrm{w}=\mathrm{W} \exp \left[-\mathrm{c}(\mathrm{r} / \mathrm{R})^{2}\right],
$$

where:

$$
\begin{aligned}
& \mathrm{w}=\text { MP vertical velocity due to the rising bubble; } \\
& \mathrm{W}=\text { bubble vertical velocity; } \\
& \mathrm{R}=\text { bubble radius; } \\
& \mathrm{r}=\text { MP distance to cloud center; and } \\
& \mathrm{c}=\text { MP and bubble "velocity coupling coefficient". }
\end{aligned}
$$
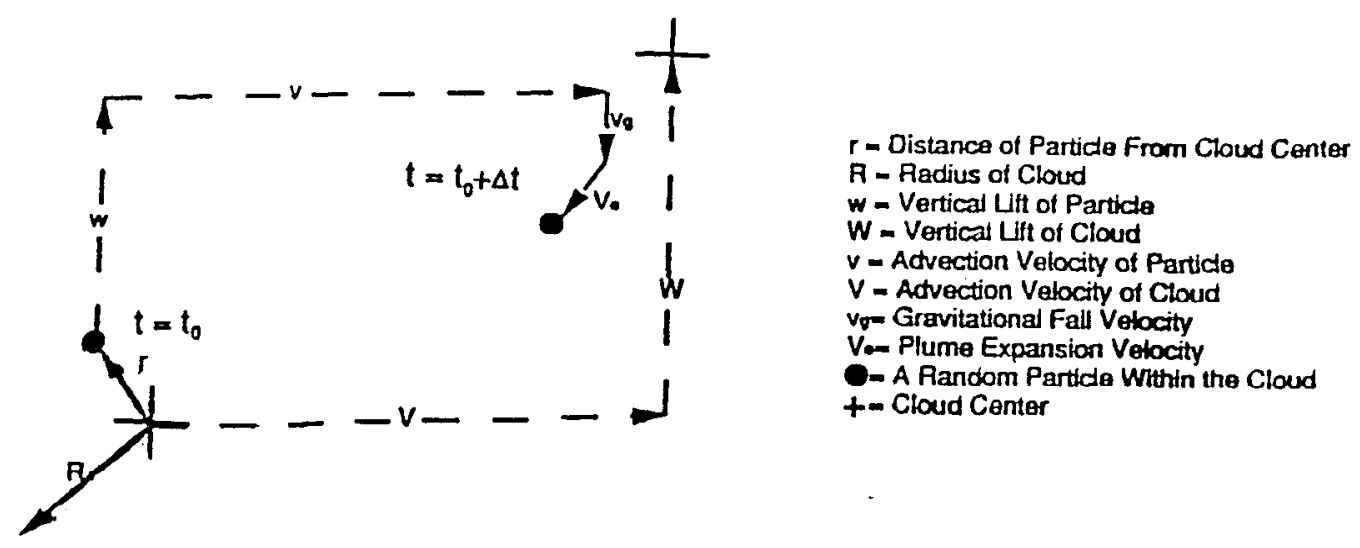
Figure 9 Two-dimensional depiction of ADPIC_EL velocities applied to the rising spherical bubble and a marker particle initially inside the bubble.

Another difference is a radial adjustment maintaining the MP relative position between the bubble center and edge as it increases in size. This adjustment "velocity" simulates effects of an expanding, well-mixed bubble by redistributing particles throughout its entire volume. This velocity due to the bubble's expansion, noted as $V_{c}$ in Figure 9, is independent of the MP movement due to MP gravitational fall $\left(\mathrm{v}_{\mathrm{g}}\right)$, MP vertical velocity (w), advection of the bubble (V), and MP advection (v). Because of spatial gradients in the advection field, $\mathrm{V}$ and $\mathrm{V}$ will not be the same. Once a particle leaves the influence of the rising bubble (usually due to the MP fall velocity), only ambient advection, diffusion, and fall velocities are applied. The dynamics of the bubble are followed until its vertical velocity decreases below a predetermined limit (presently equal to $0.001 \mathrm{~m} / \mathrm{s}$ ). At this point the bubble calculation is terminated.

A series of calculations resulted in an optimized value of 0.35 for the velocity coupling coefficient. ${ }^{20}$ Table 9 gives the parameters we used for the HED scenario studied here.

Table 9 HED parameters used in ADPIC_EL for this study.

Pu in fire $(10 \mathrm{~kg})$

Aerosolized Fraction (AF) $=1.0$

Pu Alpha Specific Activity $(0.088 \mathrm{Ci} / \mathrm{g})$

\section{Lofting Model}

Lofted Fraction (1.OAF)

Stabilization Time (2 $\mathrm{min})$

Height to Inversion $(300 \mathrm{~m})$

Surface Temperature $\left(15^{\circ} \mathrm{C}\right)$

Atmospheric Stability (neutral)

Heat of Detonation $\left(5.5 \times 10^{6} \mathrm{~J} / \mathrm{kg}\right)$

Velocity Coupling Coefficient $(0.35)$

Atmospheric Lapse Rate $\left(0.006^{\circ} \mathrm{C} / \mathrm{m}\right)$

Initial Center Height above Ground $(0 \mathrm{~m})$

High Explosive Mass (100 lbs TNT equiv)

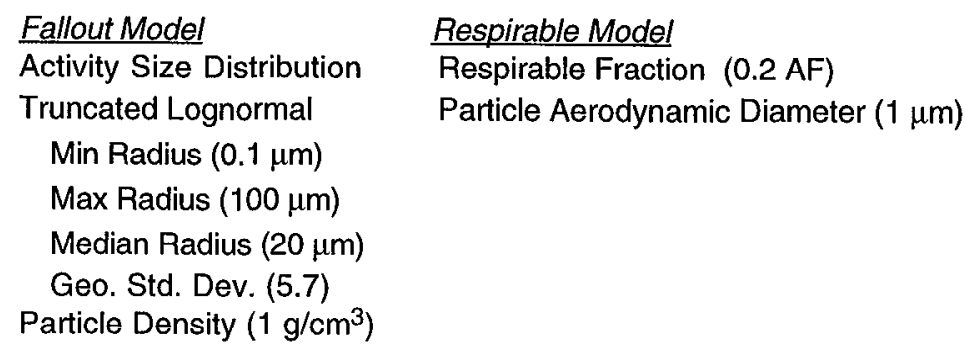

Fallout Model

Activity Size Distribution

Truncated Lognormal

Min Radius $(0.1 \mu \mathrm{m})$

Max Radius $(100 \mu \mathrm{m})$

Median Radius $(20 \mu \mathrm{m})$

Geo. Std. Dev. (5.7)

Particle Density $\left(1 \mathrm{~g} / \mathrm{cm}^{3}\right)$

Respirable Model

Respirable Fraction (0.2 AF)

Particle Aerodynamic Diameter ( $1 \mu \mathrm{m})$

\subsubsection{Unintended Nuclear Detonation Lofting}


Empirical establishment of KDFOC 325 lofted conditions may be conceptualized as a time-reversal process (see Figure 10) in which the fallout particles are projected from their landing points backward in time to an effective initial fallout cloud at 5 minutes after detonation. This "effective" cloud for a ground burst is chosen with an initially tapered stem cloud and main cloud located over ground zero (see Figure 11). To avoid the very complex problem of accurately modeling cloud rise, we empirically choose a few parameters to assign an appropriate distribution of debris with respect to altitude and particle size. The success of our procedure is tested by the model's ability to fit all the relevant NTS data.

The essence of the effective-cloud approach is to initially distribute radioactivity in a manner that accounts for variation with altitude, with "cloud radius," and particle size. For a surface burst like we study here, KDFOC3 has two radioactive debris clouds (sce Figure 11). The initial stem and main cloud distributions describe the cloud-rise and stabilization episodes. The tops, bottoms, and radii of the main cloud has large deviations about mean values. A minimum standard deviation of at least $25 \%$ is apparent in the data. This variation, however, docs not crucially affect fallout patterns.

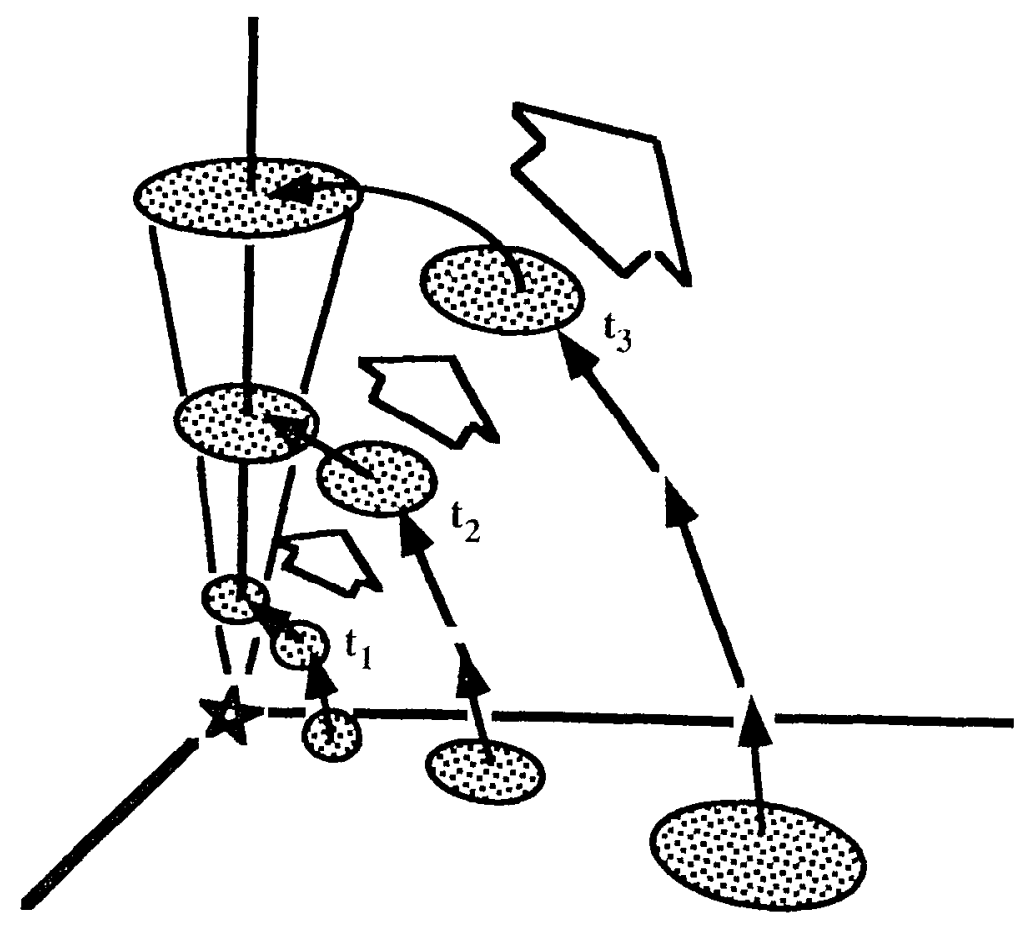

Figure 10 Schematic of time-reversed disc-tosser model. 


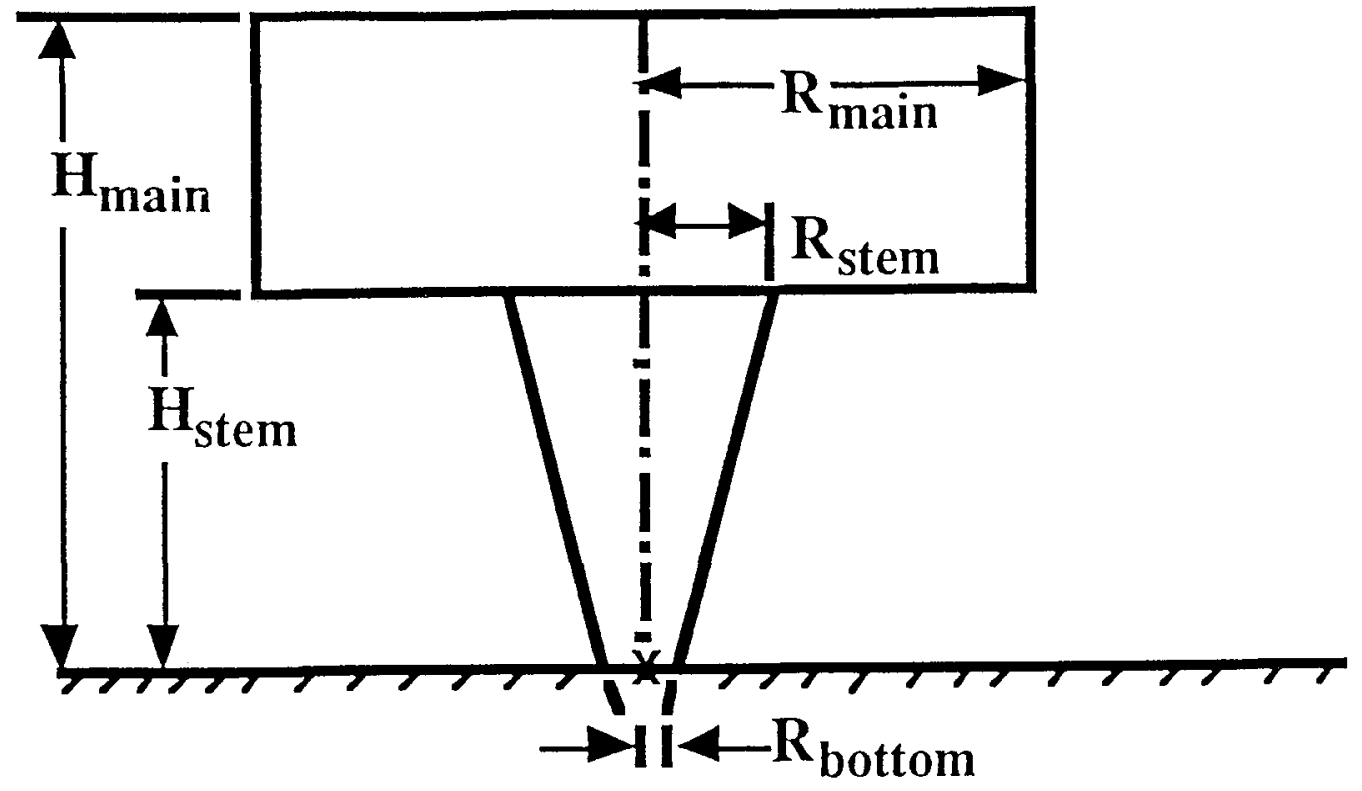

Figure 11 Schematic of KDFOC3 surface-burst "Visible Cloud Configurations" at stabilization. The $X$ indicates ground zero.

\section{- Activity-Height Distribution}

The key to empirically simulating cloud rise is to find the appropriate activity on each of NxMxJ discs, which are indices referring to cloud, height and particle-size, respectively. Besides the activity-size distribution, $\mathrm{KDFOC} 3$ uses the activity-height distribution (AHD). The ASD and AHD are highly correlated in affecting fallout patterns. This is partially accounted for by using the parameter, $u_{L}$. Also, the empirical derivation of parameters depends on choosing spherical particles of density $2.5 \mathrm{~g} / \mathrm{cm}^{3}$. A different choice would result in different AHD parameters.

Outlines of the effective clouds are shown in Figure 11. For the surface burst the activity-size distribution uses the SMALL BOY data. To fit all the fallout data, however, the $u_{L}$ from the SMALL BOY fit was changed to 0.2. The stem is tapered from three fireball radii. The stem cloud radius at its top is one-third the main-cloud radius. The taper is a linear interpolation with altitude from the bottom to top. Without the stem cloud and for typical wind and tactical yields, it is obvious from the settling velocity table that radioactivity at main cloud heights does not land within one kilometer of ground zero. Close-in activity comes from either the ground-zero circle routine or the stem cloud.

The overall vertical distribution of the airborne radioactivity is prescribed by "triangular" distribution functions of altitude: one for the small particles distribution $(k=1)$ and a second for the large $k=2$ particle sizes (for a surface burst see Figure 12). 
Each function, $A_{k}(h)$, has a mode at $h_{\bmod e}$, zeros at $h_{\max }$ and $h_{\min }$ and is normalized so that

$$
1.0=\sum_{k} \int_{h g z}^{h_{\max }} u_{k} A_{k}(h) d h
$$

where hgz is the altitude at ground zero.

The total airborne radioactivity is then assigned using the total activity-height distribution

$$
A H D(h)=\sum_{k} u_{k} A_{k}(h)
$$

for $h g z \leq h \leq h \max$.

As the debris cloud develops, the radioactivity associated with the larger particles leaves the visible debris cloud first, early in the cloud rise episode. The smaller (lighter) radioactive particles rise and stabilize within the main cloud. To incorporate this effect in the cloud-rise model, the mode of the smaller particle activity, $h_{1}$, is placed at a higher altitude than that for the larger size particles, $h_{2}$. 


\section{- Activity-Altitude-Size Model}

The combined activity-altitude-size model can be written as

$$
A(h, r)=\sum_{k} u_{k} A_{k}(h) B_{k}(r)
$$

for small and large particle sizes.

The rocket probe data of gamma rays taken on the Redwing nuclear test series indicate substantial radioactivity near the base of the main cloud at 7 minutes and 15 minutes. Thus, we have chosen a peak radioactivity for the small particles at two-thirds the stabilized height of the top of the main cloud. This is near to the main-cloud base. Because of the structure of near-field fallout patterns, we have adjusted the altitude mode of activity for the larger particles at one-tenth the top of the main cloud.

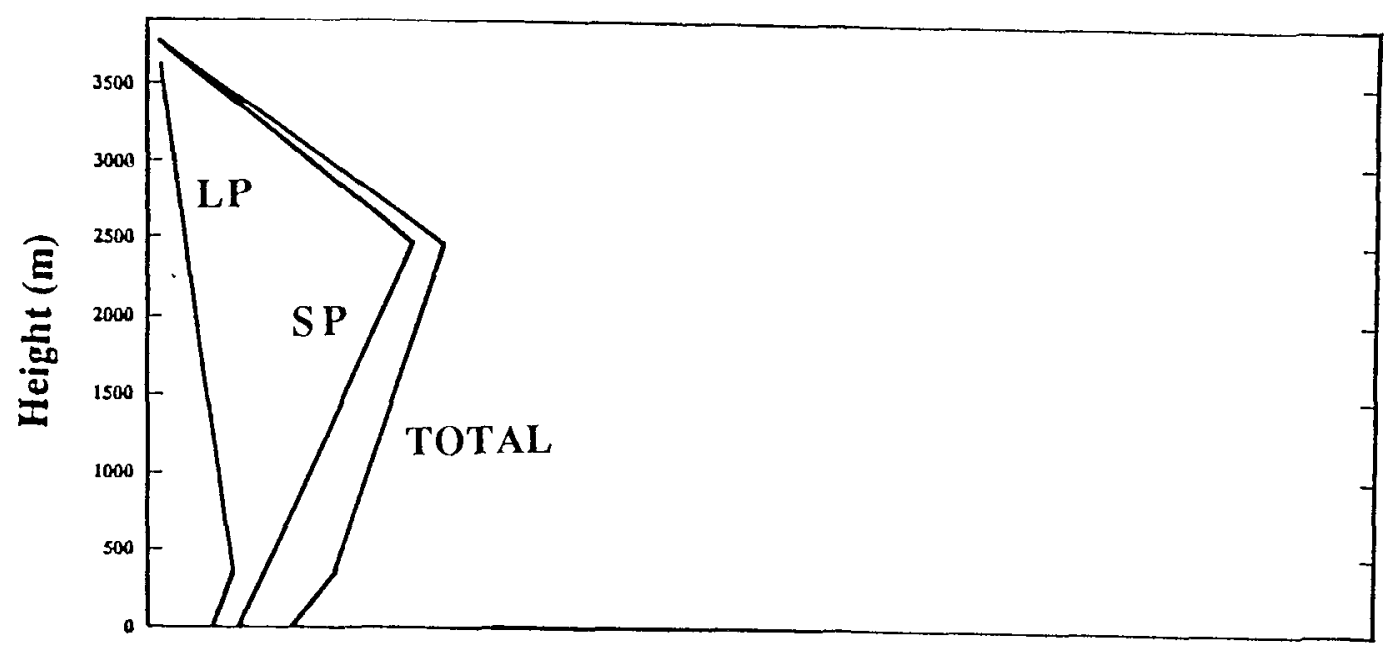

\section{Relative units}

Figure 12 Activity-height distributions for KDFOC3 at five minutes. LP shows the AHD for the larger particles; SP shows it for the smaller particles; and TOTAL is the sum of the two

\subsubsection{Activity-Size Distributions}

The activity-size distribution (ASD) is a combination of the physical-size distribution, e.g., the swept-up dirt size-distribution, and the radioactive materials deposition on the dirt, modeled as the "specific activity". In an empirical model, these are lumped together in the measurements and taken as an activity-size distribution. This, coupled with the assumption that the particles are spheres with a given density, provides a 
gravitational settling velocity for each radioactive particle. Because of the hazards we consider, there are two size distributions that concern us here: that for fallout-sized particles; and that the respirable-sized particles. The fallout ASDs are empirically determined and are different for each scenario. The respirable particles ASD's are relatively insensitive to the scenarios.

\section{- Fallout Particle Sizes}

We model the ASD of the fallout-sized particles as a lognormal distribution. Empirically, such a model seems to fit the data well. For fallout from a nuclear detonation, we use a bimodal, lognormal distribution. Equation 1 gives the general form of the fallout ASD. Values of the parameters for our three scenarios are given in Table 10. These empirical parameters have been determined from measurements.

The activity as a function of radius is given by

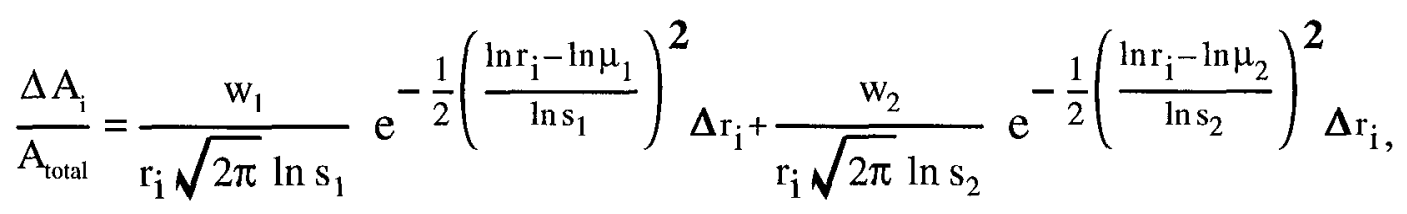

where : $\quad \Delta A_{i}=A_{i+1}-A_{i}$.

Table 10 Activity-size distribution parameters for scenarios fallout calculations (See Equation 1). The particle specific gravities are $\mathbf{1 . 0}$ for the FF and HED, and 2.5 for the UND. The initial model times are $t=0$ for the FF and HED, and five minutes for the UND.

\begin{tabular}{|l|c|c|c|c|c|c|c|}
\hline & \multicolumn{2}{|c|}{$\begin{array}{c}\text { Weighting } \\
\text { Factors }\end{array}$} & \multicolumn{2}{c|}{$\begin{array}{c}\text { Median Radius } \\
{[\mu \mathrm{m}]}\end{array}$} & \multicolumn{2}{c|}{ Geo. Std. Dev. } & $\begin{array}{c}\text { Range } \\
{[\mu \mathrm{m}]}\end{array}$ \\
\hline & $\mathbf{w}_{1}$ & $\mathrm{w}_{2}$ & $\mathrm{~m}_{1}$ & $\mathrm{~m}_{2}$ & $\mathrm{~s}_{1}$ & $\mathbf{s}_{2}$ & $\mathrm{r}_{\min } \mathbf{r}_{\max }$ \\
\hline FF & 1 & 0 & 160 & 0 & 4 & 0 & $10-500$ \\
\hline HED & 1 & 0 & 20 & 0 & 5.7 & 0 & $0.1-100$ \\
\hline UND & 0.8 & 0.2 & 14 & 150 & 4 & 2.7 & $5-500$ \\
\hline
\end{tabular}




\section{- Respirable Particle Sizes}

For respirable particles, the "respirable fraction" of $\mathrm{Pu}$ mass is determined by experiment and is given in Table 2. Gravitational settling velocity of these particles is negligible. Their movement in the atmosphere is dominated by advection and turbulent diffusion. Thus, their dispersion can be effectively modeled using a small $(1.0 \mu \mathrm{m}$ diameter) monodisperse particle. Their biological effects, however, are sensitive to size. One micrometer is a conservative diameter. We also assume unit density. Such a particle is referred to as an $\mathrm{AMAD}=1.0 \mu \mathrm{m}$ particle (activity median aerodynamic diameter particle). Their biological effects, CEDEs (defined in Section 2.1), are tabulated. Less conservative CEDFs would be assumed if we had used a larger AMAD.

\subsubsection{Cloud Dispersion Models}

We use two dispersion models for our calculation. Roughly speaking, these models take the particles generated by the source term models at some height with some settling velocity and push them through the atmosphere until they are off the grid or deposited on the ground. The model we use for the HED and FF events is the ADPIC model. It is a time-step code that moves marker particles through a 3-D wind field until they are removed by surface deposition or have floated off the grid. For the UND event we use the well-validated KDFOC3 code. It is a nuclear fallout code that is referred to by the fallout research community as a "disk-tosser." It starts with an effective stabilized cloud and analytically determines the landing location of its gaussian disks. It does not follow these disks versus time like ADPIC does its marker particles.

\section{- MATHEW/ADPIC Model}

The MATHEW/ADPIC model predicts airborne concentrations and surface deposition levels of a wide variety of pollutants as well as resultant health effects. It can handle source terms for fires and explosions.

The MATHEW ${ }^{26}$ part of the model develops a mass-consistent, three-dimensional wind field from multiple surface and upper air measurements of wind speed and direction. MATHEW generates, by variational methods, a mass-consistent, three-dimensional gridded mean wind field, including terrain from available interpolated meteorological data and topography. The input for the model consists of a digitized topographical surface, spatially interpolated surface winds, vertical wind profiles, and a stability parameter. 
ADPIC $^{27}$ follows MATHEW and is a three-dimensional, numerical diffusion and transport model capable of simulating the temporal and spatial varying dispersal of atmospheric pollutants in complex terrain. It is a particle-in-cell model in which marker particles are transported inside a fixed Eulerian grid. The model solves the threedimensional advection-diffusion equation in flux conservative form using a "pseudo velocity" technique which uses the sum of the mean wind and a diffusive velocity in the $\mathrm{x}$, $\mathrm{y}$, and $\mathrm{z}$ directions.

ADPIC computes a horizontal and a vertical diffusivity based on a semi-empirical expression. For the atmospheric surface layer the vertical diffusion is based on similarity thcory. In the outer atmospheric boundary layer it is determined using the Von Karman constant, the friction velocity, the height above terrain, and the atmospheric stability function based on the Monin-Obukhov scale length, the geostrophic wind, and the height of the mixing layer.

The M/A model has been extensively evaluated with a number of experimental data sets with a wide variety of terrain types, tracer release scenarios, and meteorological conditions including data from the Three Mile Island and Chernobyl accidents.

\section{- KDFOC3 Nuclear Fallout Model}

KDFOC 325 develops nuclear debris parcels that follow trajectories defined by the winds, turbulent diffusion, and gravitational settling. When the parcels hit the ground, their activity is summed to yield overall fallout patterns. KDFOC3 conserves radioactivity. The model is continuous in all physical parameters, both as a function of depth-of-burial and of variations in specified winds. KDFOC3 uses a unique approach to cloud-rise simulation that produces a tapered, effective stem cloud over ground zero. The success of such empirical procedures have been tested by the model's overall fit to NTS data where it achieved an agreement to measured patterns to a standard deviation of about $40 \% .25$ Its results have been compared with small yield nuclear shots, especially Little Feller II. The results agreed better than those of other models, and in all but one case, the areas and downwind distances were within a factor of two of those observed. From a fallout modeler's perspective this is very good.

Figure 13A shows the $\mathrm{Pu}$ areal contamination from a l-kt nuclear explosion calculated with KDFOC3. ${ }^{28}$ We assume there would be nearby nuclear weapons (nine of them) that would undergo HE detonations, releasing all their $\mathrm{Pu}$ to the atmosphere. Figure 13B shows plutonium inhalation doses calculated using MATHEW/ADPIC. These would be received during cloud passage. 

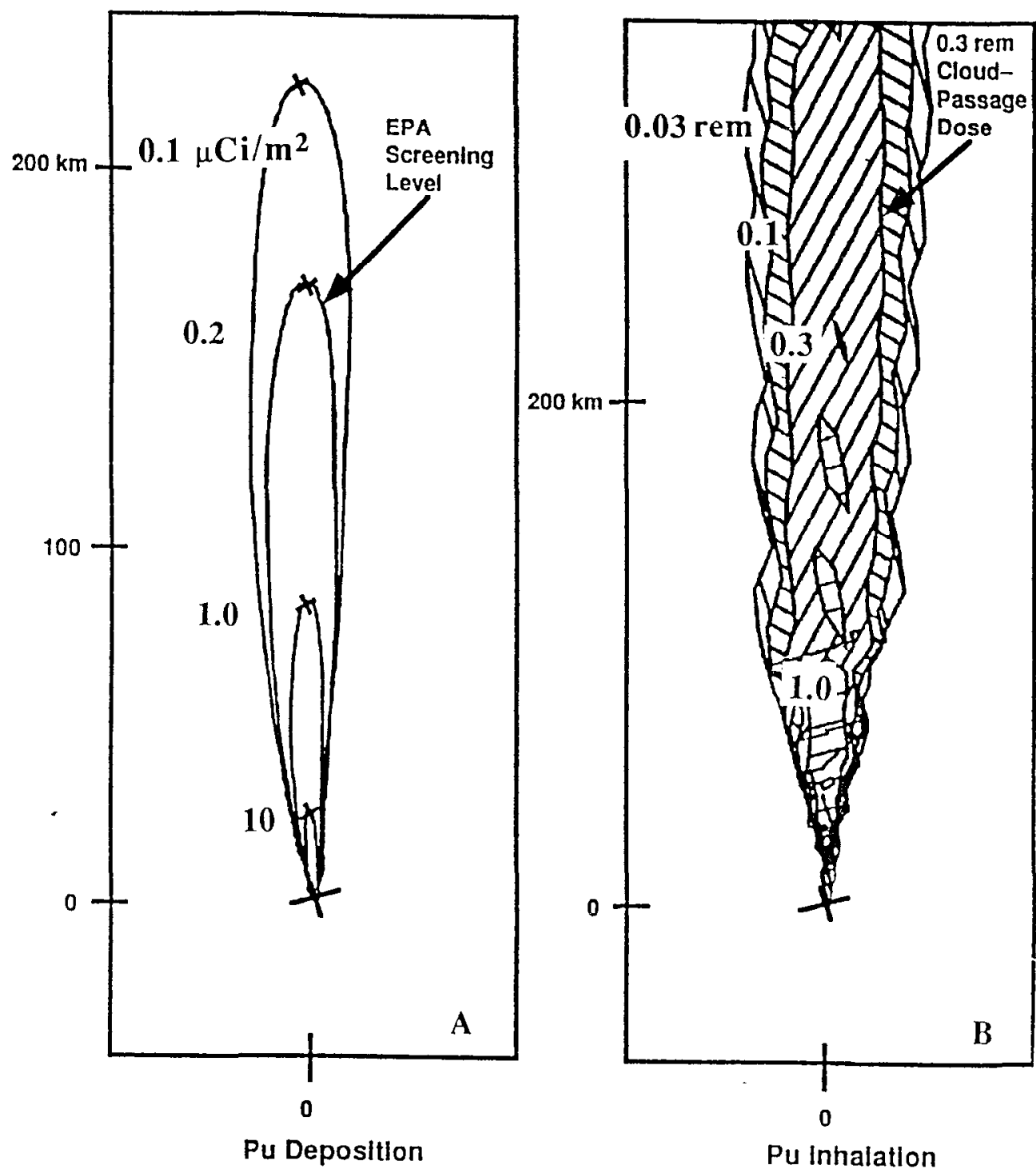

Pu Inhalation

Figure 13 Examples of areas covered for 1-kt UND. Figure 13A shows the $\mathrm{Pu}$ deposition for $100 \mathrm{~kg}$ of $\mathrm{Pu}$ dispersal. Figure 13B depicts the predicted dose from cloud passage to unsheltered individuals. Note the different distance scales.

\subsection{Nuclear Prompt Effects}

Prompt effects that are of primary concern from an accidental nuclear explosion are blast, thermal, and prompt neutron/gamma radiation. For a 1-kt surface-burst the dominant lethal effect is the neutron and gamma radiation. The dominant delayed nuclear effect is fallout gamma radiation. The largest possible doses of neutron and gamma radiation could lead to quick death from an individual's nervous system failure; lower, but very substantial doses, would cause hemorrhaging in the gastrointestinal track and death within a few days; doses around five hundred rads would lead to death in many individuals 
in about 60 days due to failure of the immune system. Between 100 rads and 500 rads there would be definite symptoms of radiation sickness, for example, nausea and loss of hair. Beta burns are caused by direct contact of the radiation with the skin and respiratory system. Longer term effects from prompt exposure to lower doses would include latent cancer fatalities and mutations in future generations.

Depending on yield, prompt effects from a nuclear explosion can dominate consequence calculations. At lowest yields, prompt gamma and neutron radiation is the most damaging effect. At larger yields, air attenuation of the prompt radiation causes blast and thermal damages to dominate. Fallout is very important and can be the dominating consequence, especially during the first several hours after an event. Figure 14 shows the prompt effects radii for blast, thermal, and prompt radiation from a fission event located on Flatland AFB. During the day, we assume that 10,000 people work on the base. At night and weekends there are 4,000 people residing in base housing. The prompt effect of blast for the HED, which is from 100 pounds of HE (roughly twenty thousand times less energy than that from the UND) is essentially negligible in comparison to that from an UND. Thermal radiation of $10 \mathrm{cal} / \mathrm{cm}^{2}$ is a major lethality criterion for large yields (1 Mt) because it is expected to cause a major firestorm with a radius of about $10 \mathrm{~km}$. Although a $1 \mathrm{kt}$ UND will start fires, it is unlikely to cause a firestorm. Thus, most deaths from low yields will be from blast at $\sim 5 \mathrm{psi}$ and initial radiation at $\sim 500$ rads.

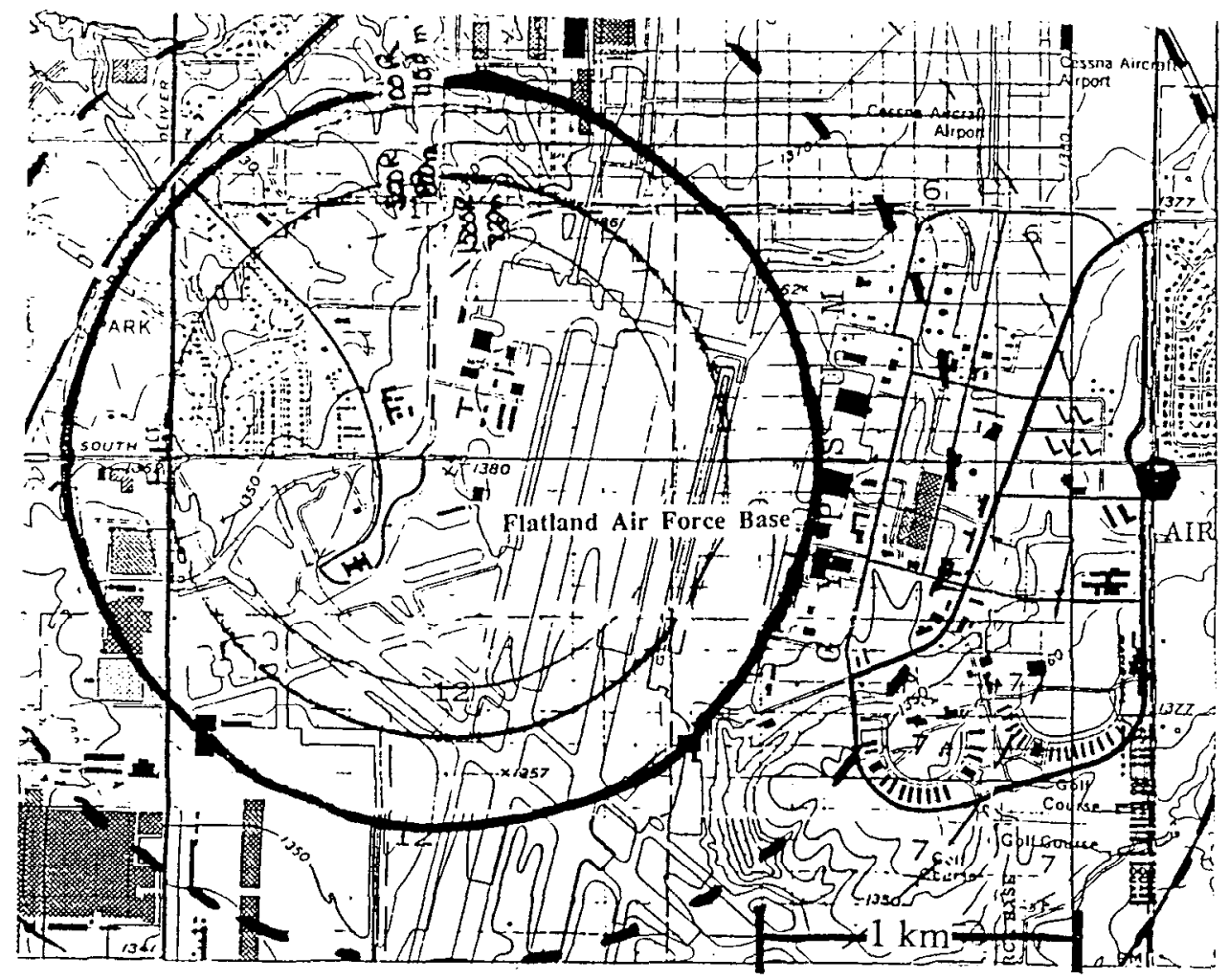


Figure 14 Prompt effects radii for initial radiation overlain on geography of Flatland AFB. Contours are 1500R, 500, 100, 10, 1 and .1.

\subsection{Population Consequences Modeling}

To estimate the possible spectrum of costs, we need a model that combines population with hazardous effects and their probabilities. A Probabilistic Consequence Assessment System has been devised for such estimates. PCAS1 is a model for doing probabilistic consequence assessments that has been used for a suite of assessments. ${ }^{1}$ It is designed to calculate consequences from nuclear device accidents, including devices undergoing assembly or disassembly, during deployment, or during transportation between facilities, within an uncertain environment. There are some important "probabilistic protocols" in the model that provide database interfaces which link probabilistic parameters and models together. The main PCAS1 results are: frequency distribution of individual doses; the areal deposition of device debris; and, the cumulative probability distribution of potential latent cancer fatalities.

To date, PCAS1 has been devised to map the U.S. population onto an appropriatesized deposition grid and to use windrose probabilities to generate cumulative collective doses. Uncertainties in respirable fraction, aerosolized fraction, and number of devices involved are possible as stochastic variables. So far, we have been mainly interested in $\mathrm{Pu}$ inhalation dose, $\mathrm{Pu}$ areal deposition, and the effects of fresh fission debris. In this study we also look at prompt effects. PCAS1 can be roughly described as consisting of five numerical models connected by probabilistic protocols: source term, meteorology, atmospheric transport, population, and health effects.

ARAC's regional transport and diffusion codes, MATHEW ${ }^{26}$ and ADPIC, ${ }^{27}$ were used to estimate the ground contamination and dose to individuals from the diffusion dominated respirable particles. The fallout dominated deposition, on non-respirable particles, was estimated using the KDFOC $3^{25}$ model. Results of the two calculations were added to give a complete analysis for all Pu particle sizes. The KDFOC3 model is used to estimate the groundshine gamma doses from the deposited fission debris.

As an example, we show the graphical results of a calculation for a ten-ton accident. To calculate the largest credible case, we used a wind blowing directly toward the nearest off-site housing development, i.e., the "ESE" wind (See Fig. 2). The groundshine gamma radiation doses received by unsheltered people in the first 24 hours are shown in Figure 15. Most of the dose is acquired in the first couple of hours. The radioactivity starts arriving at the nearby houses in the first few minutes after the accident. Dose rates from the fresh fission debris can be very high. Some of the population would show signs of radiation 
sickness. For a one-kiloton accident, instead of the ten-ton case shown here, many would receive doses above lethal levels.

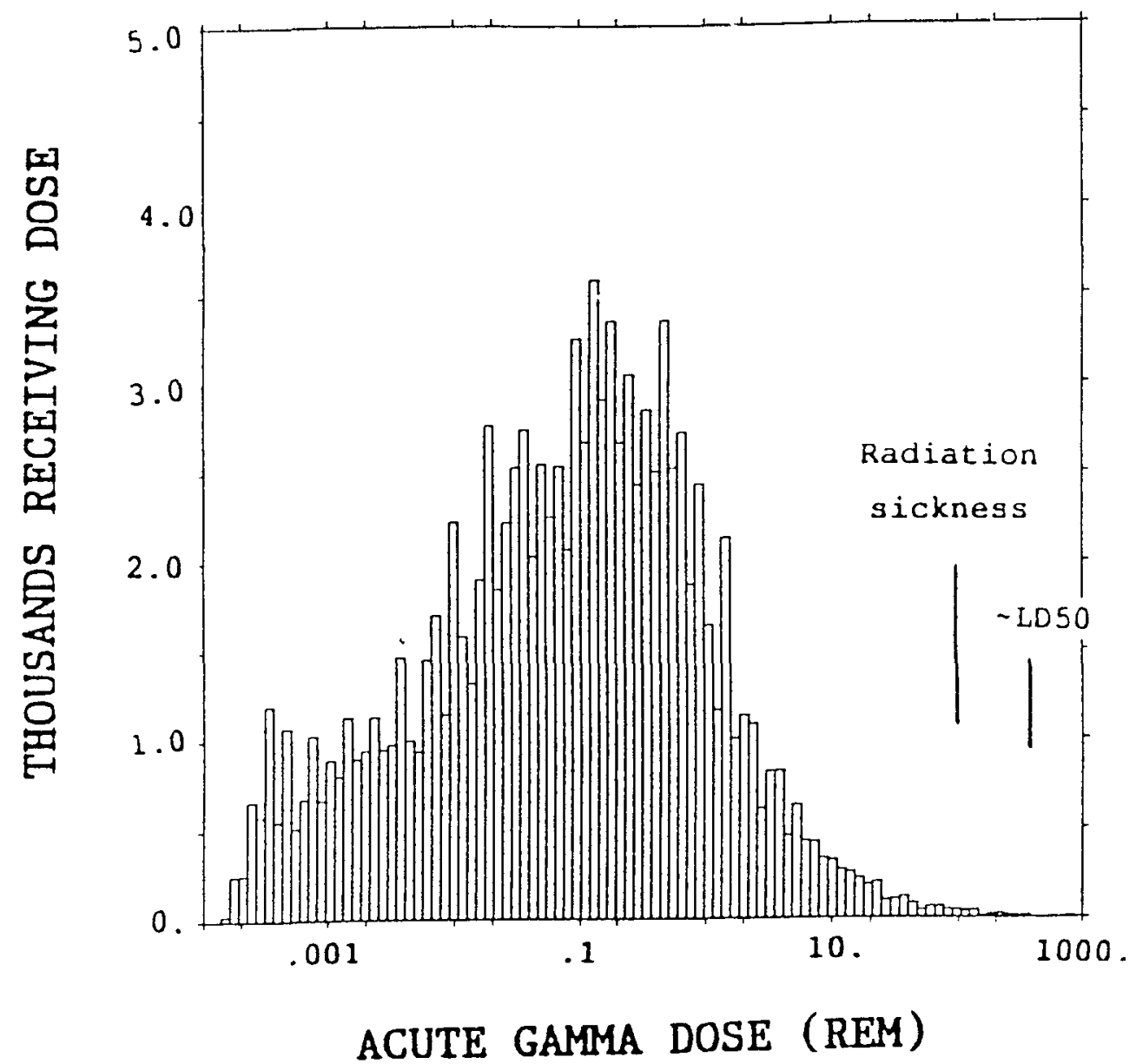

Figure 15 Ten-ton example of groundshine gamma radiation dose output received by unsheltered people in the first 24 hours.

An integrated population dose is the sum of doses to each individual of a population. Figure 16 shows the cumulative distributions of individuals receiving gamma doses greater than the dose shown for each of the sixteen wind directions given in the wind rose. The winds with the greatest consequences are winds $6,7,8$, and 5 representing winds from the ESE, SE, SSE, and E, respectively. Winds from the west, winds 10-16, cause population doses that are smaller by orders of magnitude. Unlike the $\mathrm{Pu}$ inhalation doses, these doses are not 50-yr committed doses. They are actual acute whole-body gamma doses received in the first day after the accident. 
For inhalation doses, the highest do not occur until about $10 \mathrm{~km}$ from the accident location. Whereas, the groundshine contour is most damaging around ground-zero, the inhalation dose is worse further away from GZ because the nuclear yield lofts the respirable particles to high above ground zero. They must diffuse downward to the ground before they present an inhalation hazard.

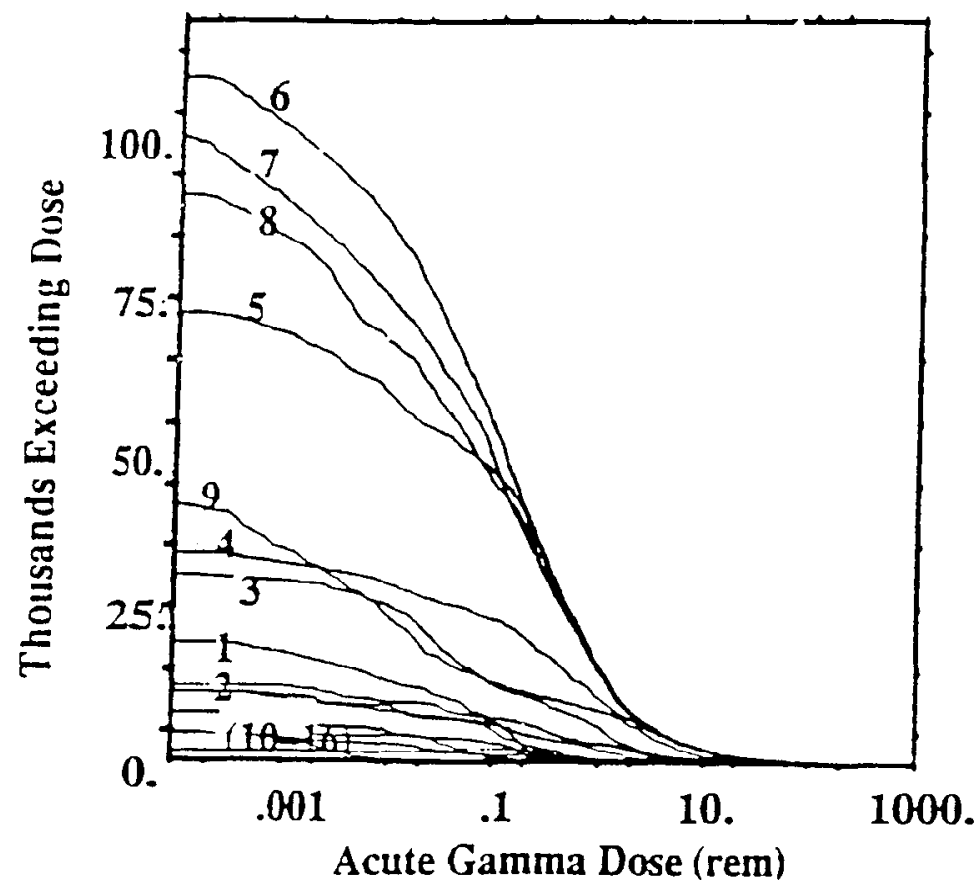

\begin{tabular}{|c|l|}
\hline Number & Wind Dir. \\
\hline 1 & N \\
2 & NNE \\
3 & NE \\
4 & ENE \\
5 & E \\
6 & ESE \\
7 & SE \\
8 & SSE \\
9 & S \\
10 & SSW \\
11 & SW \\
12 & WSW \\
13 & W \\
14 & WNW \\
15 & NW \\
16 & NNW \\
\hline
\end{tabular}

Figure 16 Ten-ton example of cumulative distributions of individuals receiving gamma doses greater than the dose shown for each of the sixteen wind directions.

The atmospheric inversion layer plays a role in the respirable doses that do occur. A less stable atmosphere without a low-lying inversion would lead to lower inhalation doses. A thermal inversion layer, that puts a ceiling on the vertical diffusion, would lead to higher doses. Higher diffusion rates in the mixing layer would lead to larger cumulative doses, because the Pu could get to the ground more quickly. For the $\mathrm{Pu}$ inhalation hazard from a nuclear explosion, effective emergency response could make a big difference in population dose received because most of the respirable aerosol takes substantial time to diffuse to the ground and because significant sheltering can be achieved from being sealed inside a building.

For gamma radiation, there is very little sheltering that occurs in residential houses for unprepared populations. In a single-family, one-story residence without a basement, a factor averaging about two reduction in dose is all the sheltering that one could expect. 
This is an average factor which includes the reduction of gamma radiation penetrating a residence or a car. Because of the rapid falloff in gamma dose rate during the first few hours, it would be very difficult for emergency personnel to enter the fallout field without receiving acute radiation problems themselves.

Ingestion of ${ }^{137} \mathrm{Cs}$ and ${ }^{90} \mathrm{Sr}$ through agricultural pathways can cause significant population damage. This is of second-order concern here and not considered are the food pathways, for example, those for ${ }^{131} \mathrm{I},{ }^{137} \mathrm{Cs}$, and ${ }^{90} \mathrm{Sr}$. Monitoring would greatly help mitigate these damages, as it has for the Chernobyl accident.

\subsection{Consequence Results}

In this section we discuss two sets of results. The first set gives our deterministic results. These depend on choosing a location, a wind direction, an atmospheric stability, a population distribution, a particle size, etc. The results are a set of exactly determined numbers; for example, 513 on-site people received greater than 100 rems of gamma radiation from fallout. The second part of this section discusses a probabilistic calculation. We look at a fuel fire and consider some of the uncertainties in the calculation, i.e., the wind direction and the aerosol respirable fraction. We display the probabilistic collective doses to demonstrate the likely ( $95 \%$ confidence level) range of results for our calculation.

\section{- Deterministic Estimates}

We refer to our non-Monte Carlo results as "deterministic estimates." Based on our choice of location of the event with respect to base housing and the civilian population directly west of the accident point (See Figs. 1 and 14), we estimate the values shown in Table 11. These estimates are conservative. We have chosen primaries with $10 \mathrm{~kg}$ of $\mathrm{Pu}$. Most weapons will have less than this, thus, damages from $\mathrm{Pu}$ dispersal would scale downward accordingly. The "best-estimate" contaminated areas in Table 11 were made using actual computer runs, with some parameter variations for low and high estimates. For LCFs and "affected population" estimates, we made qualitative allowances for population movement. People are assumed at their place of employment during the day and home at night. For example, there were assumed 10,000 people on the base during the day and 4000 at night. Different scenarios could lead to much higher or much lower consequences.

As can be seen in Table 11, consequences of an accident involving nuclear weapons could vary from moderate, in the case of a fuel fire accident, to extreme, for an unintended nuclear detonation. For example, cleanup costs based upon the draft Environmental 
Protection Agency screening level vary from 2 to $30 \mathrm{~km}^{2}$ for fuel fire accidents, to 300 to $1300 \mathrm{~km}^{2}$ for accidents involving HE detonations, to as high as 1000 to $5000 \mathrm{~km}^{2}$ for unintended nuclear detonations. Likewise, estimated numbers of latent cancer fatalities vary from much less than one for a fuel-fire accident, to a best estimate of 40 for an HE detonation, to as many as 8000 for a nuclear detonation. Prompt deaths from a 1-kt nuclear detonation on the base could vary from 100 to 2000 .

Table 11 On-site and off-site effects to individuals and property.

\begin{tabular}{|c|c|c|c|c|c|c|c|c|c|}
\hline \multirow{4}{*}{ HEALTH EFFECTS (people) } & \multicolumn{3}{|c|}{ FUEL FIRE } & \multicolumn{3}{|c|}{ HED } & \multicolumn{3}{|c|}{ UND } \\
\hline & \multicolumn{3}{|c|}{ Estimate } & \multirow{2}{*}{\multicolumn{3}{|c|}{$\begin{array}{l}\text { Estimate } \\
\text { High }\end{array}$}} & \multicolumn{3}{|c|}{ Estimate } \\
\hline & Best & High & I.ow & & & & Best. & High & Iow \\
\hline & \multicolumn{9}{|c|}{ On-site } \\
\hline Fatalities & 0 & 1 & 0 & 1 & 2 & 0 & 300 & 2000 & 100 \\
\hline Injuries & 2 & 4 & 0 & 2 & 4 & 0 & 500 & 3000 & 200 \\
\hline LCFs & 0.001 & 0.01 & 0 & 0.01 & 1 & 0 & 70 & 600 & 30 \\
\hline Affected population $\quad(>0.1 \mathrm{rem})$ & 10 & 100 & 0 & 100 & 1000 & 0 & 4000 & 10000 & 1000 \\
\hline \multicolumn{10}{|l|}{ PROPERTY DAMAGE $\left(\mathrm{km}^{2}\right)$} \\
\hline Contaminated area & 1 & 5 & 0.1 & 1 & 3 & 0.1 & 2 & 8 & 0.5 \\
\hline $\begin{array}{l}\text { Blast Area where buildings are } \\
\text { destroyed }\end{array}$ & 0 & 0 & 0 & 0 & 0 & 0 & 3 & 4 & 2 \\
\hline & \multicolumn{9}{|c|}{ Off-site } \\
\hline \multicolumn{10}{|l|}{ HEALTH EFFECTS (people) } \\
\hline Fatalities & 0 & 0 & 0 & 0 & 0 & 0 & 2,000 & 4,000 & 400 \\
\hline Injuries & 0 & 0 & 0 & 0 & 0 & 0 & 6,000 & 12,000 & 300 \\
\hline LCFs & 0.04 & 1 & 0 & 40 & 100 & 1 & 4,000 & 8,000 & 100 \\
\hline Affected population $(>0.1 \mathrm{rem})$ & 100 & 10,000 & 0 & 40,000 & 70,000 & 4,000 & 200,000 & 400,000 & 20,000 \\
\hline \multicolumn{10}{|l|}{ PROPERTY DAMAGE $\left(\mathrm{km}^{2}\right)$} \\
\hline Contaminated area & 5 & 30 & 2 & 650 & 1,300 & 300 & 2500 & 5000 & 1000 \\
\hline $\begin{array}{l}\text { Blast Area where buildings are } \\
\text { destroyed }\end{array}$ & 0 & 0 & 0 & 0 & 0 & 0 & 1 & 2 & 0 \\
\hline
\end{tabular}

\section{- Monte-Carlo Estimates}

To demonstrate approximate ranges of conscquences resulting from parameter uncertainties, as an example, we used the respirable-fraction uncertainty and wind direction uncertainty. These are two of the more sensitive uncertainties in calculating LCFs. There are many other uncertainties that could also be included. This would have the effect of expanding the range of results even further. Inhalation dose isopleths are rotated and overlaid on the population distribution for each of the sixteen points of the measured windrose. The windrose parameters (showing the probabilities in the direction from which the wind blows) are given in Table 12. 
Table 12 Sixteen-point windrose measured at Flatland AFB.

\begin{tabular}{|c|c|c|c|c|c|c|c|c|}
\hline Direction & N & NNE & NE & ENE & E & ESE & SE & SSE \\
\hline$(\%)$ & 12.4 & 5.7 & 3.9 & 3.6 & 5.7 & 3.8 & 6.3 & 14.0 \\
\hline Direction & S & SSW & SW & WSW & W & WNW & NW & NNW \\
\hline$(\%)$ & 21.1 & 5.9 & 2.4 & 1.8 & 2.6 & 1.7 & 3.4 & 6.1 \\
\hline
\end{tabular}

The uncertainty in the $\mathrm{Pu}$ respirable particle fraction from a fuel fire is a strong function of the fire characteristics. It depends on how long the device is immersed in the fire. If metallic $\mathrm{Pu}$ is exposed to a fire as a solid, the fraction released to the atmosphere would be quite small. The $\mathrm{Pu}$ metal coats itself with a $\mathrm{PuO}_{2}$ barrier that resists further effects of the fire. If, however, the Pu melts before it is exposed directly to the fire, which is possible, the resulting liquid droplets would fume and burn on contact with air, releasing one- to two-orders of magnitude more $\mathrm{Pu}$ in the respirable size range. Thus, we have chosen an uncertainty distribution that ranges from small values seen in controlled laboratory experiments with metallic $\mathrm{Pu}$ being burned to those much larger values demonstrated by British researchers when liquid droplets fume and burn. The cumulative distribution used is shown in Fig. 17. It is a truncated lognormal distribution normalized over two geometric standard deviations with a median of $0.005 \%$. It ranges from $0.0025 \%$ at the lower end to $1 \%$ at the upper end, which approximately covers our $95 \%$ confidence range.

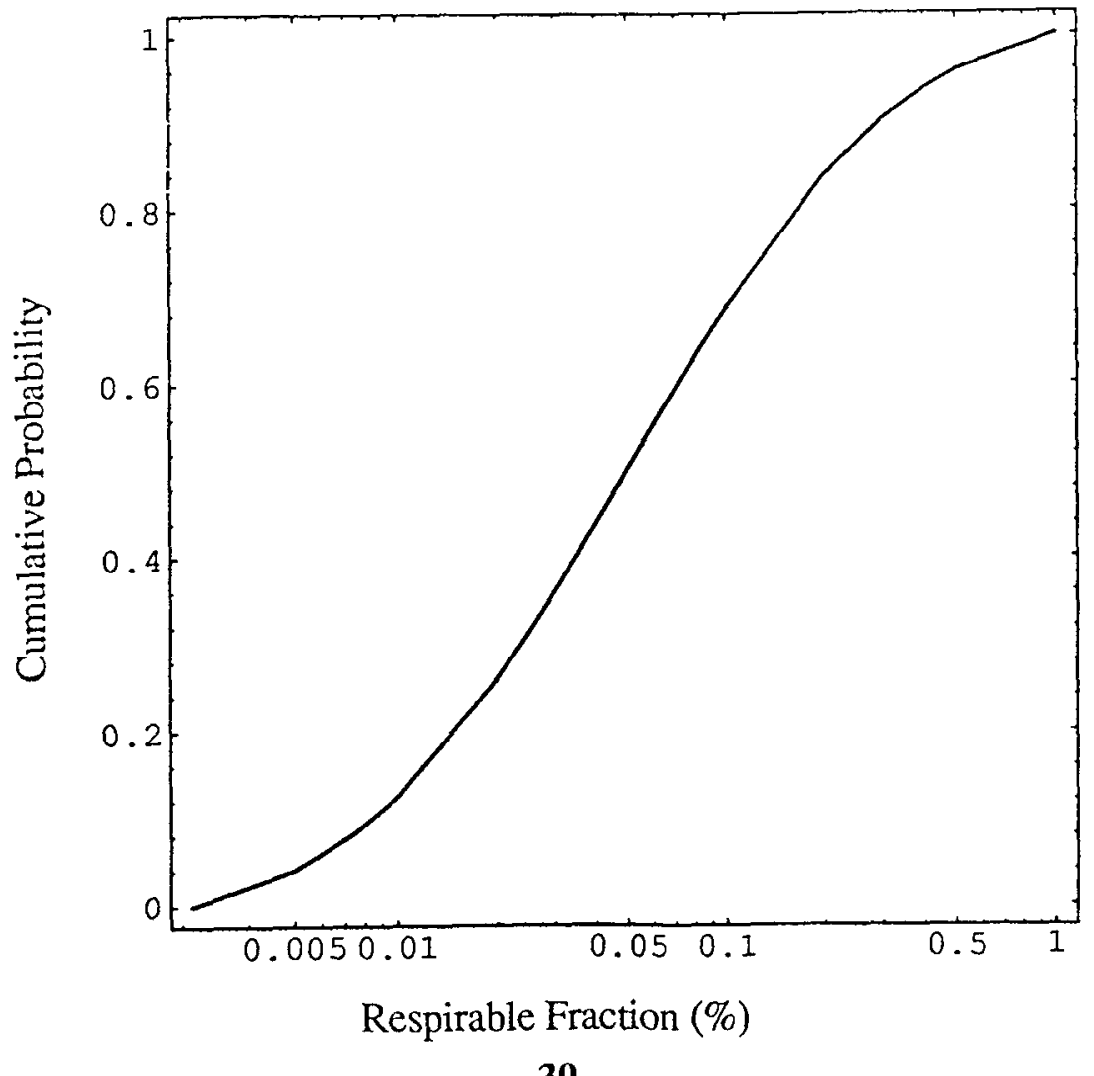


Figure 17 Respirable fraction cumulative probability distribution function. The derivative of this curve is the probability distribution function which would look like a gaussian curve when plotted on this semi-log plot. It would be skewed to the right if plotted on a linear-linear plot.

Figure 18 has been derived with a Monte Carlo calculation. The main lesson learned is that the resulting population-dose curve from the propagation of the two discussed uncertainties ranges from 0.7 to 3000 person-rem. This is across almost four orders-of-magnitude. The median value is roughly 100. Its lower bound is always above zero. Thus, it is reasonably well-represented by a lognormal distribution. The geometric standard deviation $\left(\sigma_{\mathrm{g}}\right)$ is roughly ten. Incorporating more uncertainties in the calculation would flatten the curve even further. This would lead to a larger $\sigma_{\mathrm{g}}$. We have used such findings to help establish our probabilistic cost curves in previous analyses. Such cost consequence curves have large uncertainties, making it very difficult to choose one cost strategy over another.

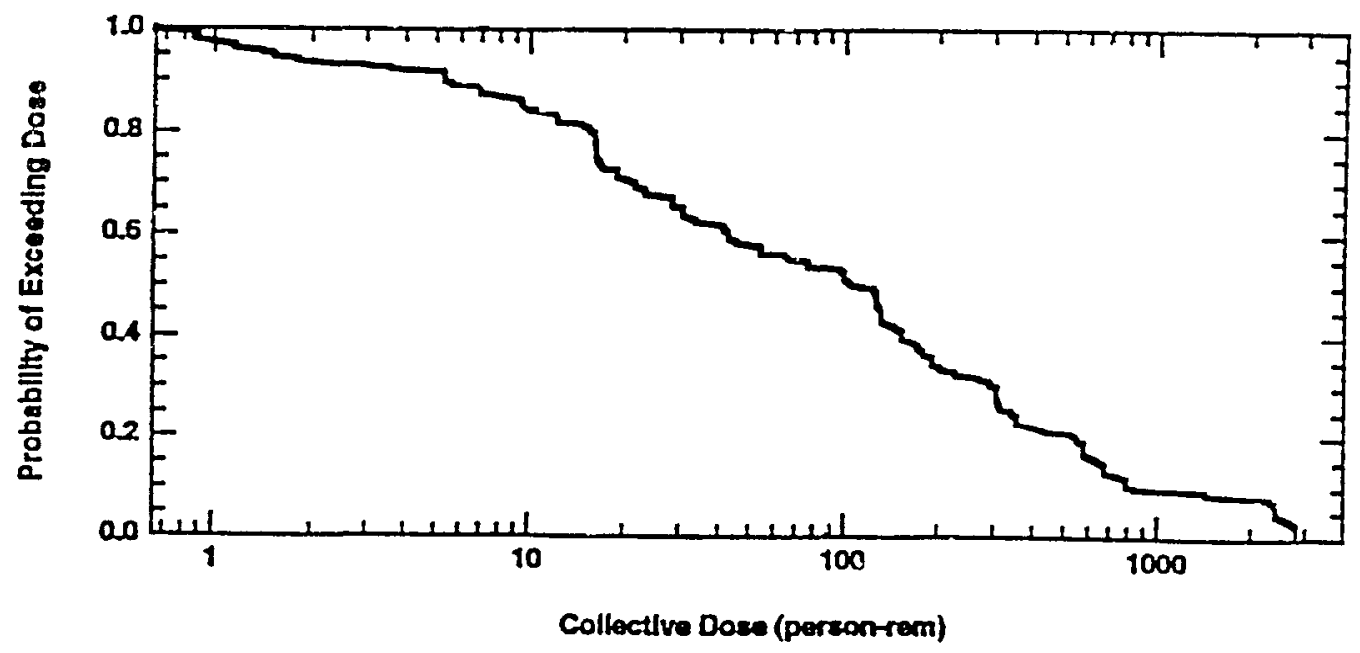

Figure 18 Probabilistic population exposure in person-rem for a fuel-fire accident at FAFB. Uncertainties explicitly included in the Monte-Carlo analysis were the wind directions and the respirable fraction of the plutonium aerosol. 


\section{Notes and References}

1. D. Stephens, C. Hall, G. Holman, T. Harvey, and F. Serduke, "Probabilistic Cost-Benefit Analysis of Enhanced Safety Features for Strategic Nuclear Weapons at a Representative Location", UCRL-JC-115269, LLNL, Livermore CA 94550, prepared for submittal to PSAM-II: Conference on Probabilistic Safety and Management, San Diego, CA March 1994,

-T. Harvey, L. Peters, F. Serduke, and L. Edwards, "Probabilistic Consequence Study of

Residual Radiological Effects from a Hypothetical Ten-Ton Inadvertent Nuclear Yield", UCRL-ID-115874, February 1994, LLNL Livermore CA 94550.

-F. Serduke, T. Harvey, and J. Ellis, "MegaHorrible - Atmospheric Dispersal Events", Q-Div Doc., DDV-940033, September 1994, LLNL Livermore CA 94550

F. Serduke and T. Harvey, "Probabilistic Cost-Benefit Analysis: A Closer Look at the Distributions", Atmos. Sci. Div. Doc. UASG \#94-6, March 1994, LLNL Livermore CA 94550

-authors list, "Value-Impact analysis of enhanced safety features for strategic nuclear weapons", UCRLJC-114202 EXT ABS, May 1993, LLNL Livermore CA 94550

-•authors list, "Max-Cred Incident of Plutonium Dispersal by Fuel Fire: A Pernicious Accident", March 1992, Q-Division Doc., DDV 92-0021, LLNL Livermore CA 94550

-authors list, "Draft Supplemental Environmental Impact Statement - Deployment of Peacekeeper Missiles in Minuteman Silos in Wyoming", Federal Court Records, Roy B. Romer. et al. v. Richard Cheny, et al., No. 84-L423 (E.D.Neb.), August 1991

2. By weight, weapons grade uranium is about a factor of 4000 less hazardous than $\mathrm{Pu}$. It can in principle be reduced by another factor of 30 by laser isotope separation. Thus, we shall focus on the Pu hazard for the rest of this discussion. Note, however, for certain accident scenarios, even though small, uranium dispersal would be the dominant hazard.

3. -A.F. Eidson, H.C. Yeh, and G.N. Kanapilly, "Plutonium Combustion Aerosols", Lovelace Inhalation Toxicology Research Institute, Albuquerque, NM, 1985.

•K. Stewart, "Vixen-A Experiments," Private Communication, AWRE, 1959.

4. The windrose measurements were made $6.0 \mathrm{~m}$ above the surface. The mean speed is $5 \mathrm{~m} / \mathrm{s}$. We used $4 \mathrm{~m} / \mathrm{s}$ as our surface wind speed, a conservative value for Pu inhalation. Ambient surface temperature was chosen as $288 \mathrm{~K}$ obtained from U.S. Air Force, Environmental Technical Applications Center, Scott AFB, IL 62225.

5. This is for the ICRP "Standard Man" undergoing light activity and no mitigating factors, i.e., no sheltering. (General public breathing rate is $\sim 1.9 \times 10^{-4} \mathrm{~m}^{3} / \mathrm{sec}$.)

6. International Commission of Radiological Protection, ICRP/60/G-01, February 1990.

7. Health Effects of Exposure to Low Levels of lonizing Radiation, BEIR-V, National Academy Press, Washington, D.C. (1990).

8. R.F. Carter and K. Stewart, "On the Oxide Fume Formed by the Combustion of Plutonium and Uranium," BOHS Symposium Inhaled Particles III, 1970.

9. G. Burley, "Transuranium Elements-Technical Basis for Remedial Actions," Vol. II, EPA 520/1-90-016, Office of Radiation Programs, U.S. Environmental Protection Agency, Washington, D.C. 20460, June 1990. "Persons Exposed to Transuranium Elements in the Environment," Federal Register, 42 (230) (60956), 1977; also, "Interim Recommendations on Doses to Persons Exposed to Transuranium Elements in the General Environment," U.S. Environmental Protection Agency, Washington, D.C., Draft, 1987.

10. Consideration of terrorists' events, either using a stolen weapon or a so-called, low-technology "improvised nuclear device" (IND) is beyond the scope of this work. A terrorist scenario would be entirely different from 
the three considered here, both from frequency-of-occurrence and location considered. A terrorist act would be far more likely to occur in a highly visible, developed, and populated region (e.g., the World Trade Center) than the accident location considered in this report. If the IND worked, it would also likely be at higher fission yield than the 1-kt weapon considered here.

11. A MCi is $3.7 \times 10^{16}$ disintegrations per second.

12. S. Glasstone and P. Dolan, The Effects of Nuclear Weapons, 3rd edition, DoD and ERDA, 1977.

13. E. Segre, Nuclei and Particles: An Introduction to Nuclear and Subnuclear Physics, W. A. Benjamin, Inc. New York, 1965, p.491.

14. The EPA screening level is $0.2 \mu \mathrm{Ci} / \mathrm{m}^{2}$. However, this has not been formally promulgated as a de minimus level. A precedent has been established for government action below this level. The government has purchased land at Rocky Flats, apparently to avoid litigation.

15. Sheltering and evacuation are difficult actions and are not likely to mitigate the effects of gamma radiation. We have also ignored immersion and cloudshine doses because they are substantially less severe than the more enduring groundshine.

16. For Chernobyl, the dominant radionuclide was ${ }^{137} \mathrm{Cs}$ because it is much more volatile than ${ }^{90} \mathrm{Sr}$. Most of the ${ }^{137} \mathrm{Cs}$ was released, whereas only a small fraction of ${ }^{90} \mathrm{Sr}$ was released.

17. R. W. Homsy, L. L. Edwards, T. F. Harvey, E. L. Lee, E. H. Moor, L. G. Peters, J. R. Walton, and A. Weston, "Plutonium Release Probabilities and Consequences for Peacekeeper in Minuteman Silos (PIMS)," Report DDV91-0031, July 22, 1991.

18. G. Briggs, "Plume Rise Predictions," Lectures on Air Pollution and Environmental Impact Analyses (ed. Haugen), American Meteorological Society, 1975, pp. 53-111.

19. G. Briggs, "Plume Rise and Buoyancy Effects" in Atmospheric Science and Power Production, U.S. DOE, Washington, D.C., DE84-005177 (327), 1984.

20. K. Foster, R. Freis, and J. Nasstrom, "Incorporation of an Explosive Cloud Rise Code into ARAC's ADPIC Transport and Diffusion Model," Lawrence Livermore National Laboratory, Livermore, CA, UCRL-ID-103443, 1990.

21. M. Beychok, "Fundamentals of Stack Gas Dispersion," M. Beychok, 63 Oak Tree Lane, Irvine, CA 92715, 1979.

22. B. A. Boughton, and J. M. Delaurentis, "An Integral Model of Plume Rise from High Explosive Detonations," 1987 ASME/AIChE National Heat Transfer Conference, August 9-12, Pittsburgh, PA, 1987.

23. P. H. Gudiksen, R. Lange, D. J. Rodriguez, and J. S. Nasstrom, "The Use of Field Experimental Studies to Evaluate Emergency Response Models," Lawrence Livermore National Laboratory, Livermore, CA, UCRL92342, 1985.

24. K. Stewart, Roller Coaster: Summary Report (U), U.K. Atomic Energy Authority Report AWRE No. T6/69, 1969 (Secret). 
25. T. Harvey, F. Serduke, L. Edwards and L. Peters, "KDFOC3: A Nuclear Fallout Assessment Capability" UCRL52338, Lawrence Livermore National Laboratory, 1992, DRAFT; KDFOC3 is a widely accepted model and was empirically developed for fallout predictions during the last three decades. It has been validated against many observations spanning a large range of measurements.

26. C. Sherman, "A Mass-Consistent Model for Wind Fields over Complex Terrain," J. Appl. Meteor., 17, 312, 1978.

27. R. Lange, "ADPIC-A Three-Dimensional Particle-In-Cell Model for the Dispersal of Atmospheric Pollutants and its Comparison to Regional Tracer Studies," J. Appl. Meteor. 320, 1978.

28. For an UND, nuclear weapons that might be in close proximity would at least undergo sympathetic HE detonations. Pu would be lofted as fallout particles from these weapons too; thus, there could be many times the amount of Pu that would occur from a single weapon. 
1000 rem

500 rem

300 rem

LP

SP

TOTAL

$0.1 \mu \mathrm{Ci} / \mathrm{m}^{2}$

$0.2 \mu \mathrm{Ci} / \mathrm{m}^{2}$

$1.0 \mu \mathrm{Ci} / \mathrm{m}^{2}$

$10 \mu \mathrm{Ci} / \mathrm{m}^{2}$

0.01 rem

0.03 rem

0.1 rem

$0.3 \mathrm{rem}$

$1.0 \mathrm{rem}$ 


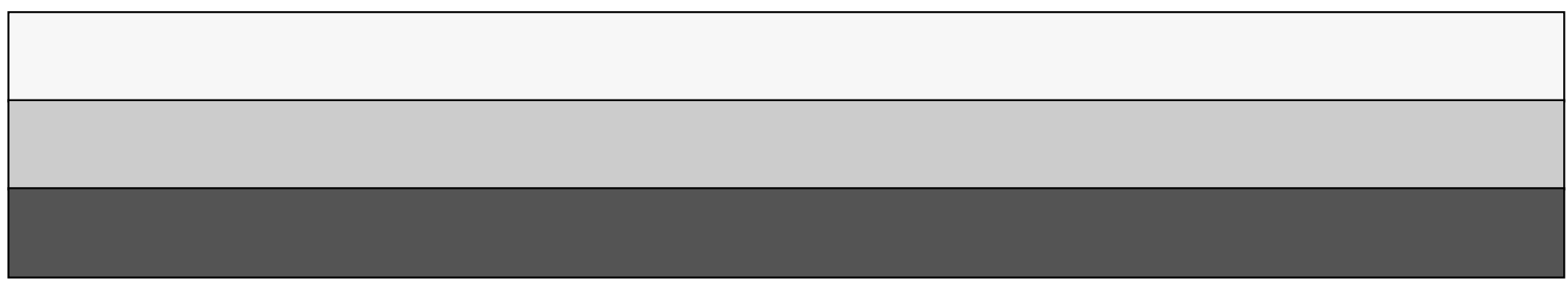

